\title{
Metabolite Profiles of Nodulated Alfalfa Plants Indicate That Distinct Stages of Nodule Organogenesis Are Accompanied by Global Physiological Adaptations
}

\author{
Aiko Barsch,, ${ }^{1,2}$ Verena Tellström, ${ }^{1}$ Thomas Patschkowski, ${ }^{3}$ Helge Küster, ${ }^{2,3}$ and Karsten Niehaus ${ }^{1}$ \\ ${ }^{1}$ Proteom und Metabolomforschung, Fakultät für Biologie, Universität Bielefeld, Postfach 100131, D-33501 Bielefeld, \\ Germany; ${ }^{2}$ International NRW Graduate School in Bioinformatics and Genome Research, Universität Bielefeld, \\ Postfach 100131, D-33501 Bielefeld, Germany; ${ }^{3}$ Lehrstuhl für Genetik, Fakultät für Biologie, Universität Bielefeld, \\ Postfach 100131, D-33501 Bielefeld, Germany
}

Submitted 22 February 2006. Accepted 9 May 2006.

An effective symbiosis between Sinorhizobium meliloti and its host plant Medicago sativa is dependent on a balanced physiological interaction enabling the microsymbiont to fix atmospheric nitrogen. Maintenance of the symbiotic interaction is regulated by still poorly understood control mechanisms. A first step toward a better understanding of nodule metabolism was the determination of characteristic metabolites for alfalfa root nodules. Furthermore, nodules arrested at different developmental stages were analyzed in order to address metabolic changes induced during the progression of nodule formation. Metabolite profiles of bacteroid-free pseudonodule extracts indicated that early nodule developmental processes are accompanied by photosynthate translocation but no massive organic acid formation. To determine metabolic adaptations induced by the presence of nonfixing bacteroids, nodules induced by mutant $S$. meliloti strains lacking the nitrogenase protein were analyzed. The bacteroids are unable to provide ammonium to the host plant, which is metabolically reflected by reduced levels of characteristic amino acids involved in ammonium fixation. Elevated levels of starch and sugars in $\mathrm{Fix}^{-}$nodules provide strong evidence that plant sanctions preventing a transformation from a symbiotic to a potentially parasitic interaction are not strictly realized via photosynthate supply. Instead, metabolic and gene expression data indicate that alfalfa plants react to nitrogen-fixationdeficient bacteroids with a decreased organic acid synthesis and an early induction of senescence. Noneffective symbiotic interactions resulting from plants nodulated by mutant rhizobia also are reflected in characteristic metabolic changes in leaves. These are typical for nitrogen deficiency, but also highlight metabolites potentially involved in sensing the $\mathbf{N}$ status.

Additional keywords: GC-MS, gene expression profiles, metabolite profiling.

Corresponding author: A. Barsch; Telephone: +49 521 106-5618; Fax: +49 521 106-5626; E-mail: aiko.barsch@Genetik.Uni-Bielefeld.DE

* The $\boldsymbol{e}$-Xtra logo stands for "electronic extra" and indicates the HTML abstract available on-line contains supplemental material not included in the print edition.
Leguminous plants associated with symbiotic bacteria of the family Rhizobiaceae are able to grow on nitrogen-starved soils. Key to this achievement is the bacterial ability to reduce atmospheric nitrogen in a functional symbiotic interaction in which ammonia is provided to the plant. The establishment of this symbiosis requires a constant fine-tuned signal exchange between plant and bacteria (Patriarca et al. 2004; Stougaard 2000). Flavonoids excreted by plant roots induce the expression of nod genes in the bacterial partner. The nod gene products are responsible for the generation of Nod factors which, in turn, induce root hair deformation and meristem induction, leading to the formation of a novel plant organ, the root nodule (Long 1996). Synthesis of acidic exopolysaccharides (EPS) by rhizobia is required for the effective infection of root nodules which harbor symbiotic bacteria within the plant cells (Müller et al. 1988). Inside the nodules, bacteria differentiate into bacteroids which are surrounded by a plant-derived peribacteroid membrane. Bacteroids synthesize the nitrogenase enzyme complex, catalyzing the reduction of atmospheric nitrogen to ammonia. The oxygen sensitivity of the nitrogenase enzyme complex contradicts the bacteroids need for ATP production in order to fuel the high energy demands of the nitrogen fixation process. Continuous supply of oxygen and concomitant microaerobic conditions are realized through the production of large amounts of leghemoglobin and an oxygen diffusion barrier in the nodule cortex (Minchin 1997).

Nodule nitrogen and ammonium fixation is fueled primarily by the plant photosynthate sucrose (Gordon et al. 1999). In a first step, sucrose is cleaved by a nodule-enhanced sucrose synthase (Hohnjec et al. 1999) and further catabolized via glycolysis in the plant cytosol (Kaminski et al. 1998). Subsequently, phosphoenolpyruvate carboxylase (PEPC) catalyzes the carboxylation of phosphoenolpyruvate to generate oxaloacetate, which can be used for aspartate or asparagine synthesis or the reduction to malate by malate dehydrogenase in order to fuel the bacteroid metabolism (Schulze 2004).

Recent technological advances allowed the analysis of complex metabolite mixtures using combinations of, for example, gas chromatography and mass spectrometry (GC-MS) (Fiehn et al. 2000), liquid chromatography and mass spectrometry (LC-MS) (Huhman and Sumner 2002), or capillary electrophoresis and mass spectrometry (CE-MS) (Soga et al. 2003). Application of these methods on nodulated Lotus japonicus plants led to a better understanding of the metabolism involved 
in nodule development (Colebatch et al. 2004) and enabled the identification of marker metabolites characteristic for the nodule tissue (Desbrosses et al. 2005). The combination of metabolomic and transcriptomic data allowed the proposition of a model explaining the observation of enhanced malate synthesis in nodules, presumably as a result of low oxygen and phosphorous concentrations (Colebatch et al. 2004).

Another important approach in understanding the complex interaction of the interlocked bacteroid and plant metabolism is the use of targeted analyses of defined metabolites. Bacterial and plant mutants defective in symbiotic interactions proved to be valuable tools for elucidating many aspects of the multistage sequence of interdependent steps leading to the establishment and maintenance of root nodule metabolism (Kahn et al. 1998; Randhawa and Hassani 2002; Vincent 1980). Furthermore, the study of different mutants indicated the presence of transcriptionally distinct checkpoints during nodule organogenesis (Mitra and Long 2004). This finding suggested a coordinated symbiotic development by alternating control of both partners, although the underlying mechanisms remain still elusive.

The symbiotic interaction between the soil bacterium Sinorhizobium meliloti and its agriculturally important host plant Medicago sativa (alfalfa) or the model legume $M$. truncatula serves as a well-established system to study symbiotic plantmicrobe interactions on a molecular level (Cook 1999). Several bacterial mutants are known to induce the formation of nodules but are incapable of infection $\left(\mathrm{Inf}^{-}\right)$. The exo Y mutant strain $S$. meliloti 0540 does not synthesize exopolysaccharides (EPS ${ }^{-}$) (Müller et al. 1988) and, thus, is unable to induce infection threads that extend beyond the base of the root hairs (Cheng and Walker 1998). The formed bacteroid-free pseudonodules are unable to perform the nitrogen fixation process. Nevertheless, pseudonodules accumulate high amounts of starch (Niehaus et al. 1993), indicating that even though these nodules do not provide reduced nitrogen to the plant, photoassimilate transport into the nodules is not completely turned off. Comprehensive metabolite analyses of these plants compared with plants infected with wild-type bacteria might provide important information on physiological adaptations induced in nodules arrested at this early developmental stage.

The bacterial nitrogenase complex is encoded by the nifHDK genes. All three genes form an operon transcribed in the direction from nifH to nifK (Ruvkun et al. 1982). A transposon insertion in the nif $\mathrm{H}$ gene is polar and leads to a nif $\mathrm{HDK}^{-}$phenotype (Hirsch et al. 1983). Nodules induced by nifH mutant $S$. meliloti strains contain bacteroids unable to fix atmospheric nitrogen $\left(\mathrm{Inf}^{+}, \mathrm{Fix}^{-}\right)$. Metabolically, these nodules should resemble the pseudonodules induced by S. meliloti 0540 because both cannot provide ammonia to the plant and require far less photoassimilates than nodules invaded by wild-type bacteria. Nevertheless, it can be expected that the presence of bacteroids influences the overall metabolite profile of the nodule. Several studies revealed that Fix ${ }^{-}$nodules show early senescence, whereas pseudonodules show fewer signs of lysis (D. Kapp, personal communication). Therefore, metabolic data derived from $\mathrm{Fix}^{-}$nodules might reveal potential physiological plant responses triggered by the presence of noneffective bacteroids.

The present study employed a nonbiased metabolite profiling method based on GC-MS to analyze metabolic changes in alfalfa nodules and leaves induced by wild-type and Sm1021

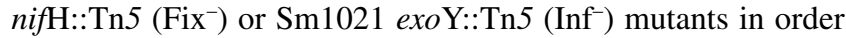
to address global nitrogen $(\mathrm{N})$ regulation in nodulated alfalfa. Furthermore, metabolite and gene expression studies of nodulated plants arrested at different developmental stages were used to understand defined aspects of the symbiotic interaction, finally contributing to a better understanding of the global regulation of nodule formation.

\section{RESULTS}

Metabolite profiling analyses revealed characteristic compounds for alfalfa root nodules.

In order to understand the global regulation of nitrogen and carbon metabolism in nodulated alfalfa plants, it seemed reasonable to first determine metabolic features that are characteristic for the symbiotic interaction of M. sativa and S. meliloti. A comparison of the relative metabolite abundances in nodules versus other plant tissues may identify characteristic metabolites specific for nodules, as was shown recently for L. japonicus in symbiosis with Mesorhizobium loti (Desbrosses et al. 2005). Therefore, a comparative analysis of the hydrophilic metabolite profiles of alfalfa nodules and roots was performed by GC-MS.

Medicago sativa plants infected with wild-type $S$. meliloti 1021 bacteria were analyzed 21 days postinoculation (dpi). The different GC-MS chromatograms of nodule and root extracts contained approximately 200 peaks, of which 67 could be identified by comparison with purified standards. The abundances of 80 selected metabolites (identified or unknown) routinely were determined by integrating the peak areas of handpicked characteristic mass fragments for each metabolite. Typically, the abundance of some metabolites (e.g., glyceric acid 3-P, phosphoenolpyruvate [PEP], and cysteine) was very low in several extracts and the mass spectra had a low signalto-noise ratio. These metabolites could be identified only by certain characteristic fragment ions compared with mass spectra of purified standards. Therefore, these mass fragments routinely were used for quantification, always considering the latent ambiguities of the obtained results.

Furthermore, it is likely that arginine and citrulline may be converted into ornithine during the derivatization process (Desbrosses et al. 2005; Halket et al. 2005). As a result, the measured ornithine in metabolite extracts represents the combined amount of ornithine, arginine, and citrulline extracted from the samples.

For a preliminary analysis of the complex dataset obtained from the 42 samples ( 21 root and nodule samples derived from three biological replicates), a multivariate data mining technique was applied. Principal component analyses (PCA) of the normalized relative response ratios (discussed below) calculated from the hydrophilic metabolite extracts clearly could separate the biological samples according to their nodule or root origin.

Significant differences $(P<0.01)$ between samples from nodules and roots were determined by comparing the respective normalized relative response ratios using the $t$ test. The ratios of 61 nodule and root metabolites that could be identified compared with purified standards are shown in Table 1. Several other metabolites were significantly altered in both tissues, but these compounds remain unidentified. Interestingly, all analyzed amino acids except cysteine were increased significantly in the nodule tissue. In particular, the ratios of asparagine, glutamine, alanine, isoleucine, leucine, lysine, valine, and proline showed a marked increase. Furthermore, the organic acids 2-aminoadipic acid, fumaric acid, and succinic acid, as well as spermidine and urea, were explicitly elevated in nodule tissue. The sugars glucose and maltose exhibited no significant differences between the analyzed plant organs, whereas fructose and sucrose were more abundant in nodule tissue. Several phosphorylated metabolites, such as glycerol-3-P, glyceric acid-3-P, ribose-5-P, and glucose-6-P, were significantly increased in nodules, whereas fructose-6-P was similarly abundant in roots and nodules. A compound which was much more abundant in nodules than in roots showed mass spectral similarity to purified DL-2-methylcitric acid and threo-2-methylisocitric acid (provided by W. Buckel, Universität Marburg, Germany). Nevertheless, the retention time for this putative methylcitric acid did not match either 
of the standards. Interestingly, the mass spectrum of this metabolite did match (match value $>800$ ) a structurally not unambiguously characterized methylcitric acid isolated from $L$. japonicus nodules (Desbrosses et al. 2005) which was identified as a marker substance for this nodule type.

In summary, a characteristic metabolic "marker pattern" for alfalfa root nodules was identified. Some of these metabolites also were shown to be characteristic for $L$. japonicus nodules (Desbrosses et al. 2005).

\section{Global analysis of nodule metabolite profiles} from infection or fixation mutants of $S$. meliloti.

In parallel to the plants inoculated with wild-type Sm1021 used for the comparison of root and nodule metabolites (discussed above), $M$. sativa seedlings were inoculated with Sm1021 exoY::Tn5 or Sm1021nifH::Tn5. In order to generate these mutants, the Tn5-containing regions of Sm2011 exoY::Tn5 and $\mathrm{Sm} 2011$ nif $\mathrm{H}:: \mathrm{Tn} 5$ each were transduced into the sequenced wild-type strain Sm1021. The correct transposon insertion positions were verified by sequencing the transposon-flanking genomic DNA regions of the transductants.

$M$. sativa plants inoculated with $\mathrm{Sm} 1021$ exoY::Tn5 induced typical pseudonodules, which were more spheroid and smaller than nodules induced by the wild-type strain. In accordance with previous results, the $S$. meliloti strain Sm1021 nifH::Tn5
$\left(\mathrm{Fix}^{-}\right)$usually induced nodules of similar size to wild-type nodules and showed a pink color, indicating the presence of leghemoglobin. Nodules induced by either mutant $S$. meliloti strain were incapable of nitrogen fixation $21 \mathrm{dpi}$, as determined by the acetylene reduction assay (data not shown).

Manual inspection of GC-MS chromatograms derived from hydrophilic metabolite extracts of different nodule types harvested 21 dpi clearly indicated marked and reproducible differences between the samples (Fig. 1). Striking differences in the abundances of several amino acids (e.g., asparagine, glutamate, and aspartate) were immediately noticeable between nitrogenfixing wild-type nodules and nonfixing nodules induced by the mutants.

In accordance with the GC-MS results obtained from roots and wild-type nodules, the chromatograms derived from extracts of nodules induced by Sm1021 exoY::Tn5 and Sm1021 nif $\mathrm{H}: \mathrm{Tn} 5$ contained approximately 200 compound peaks; however, no further metabolites could be identified in these extracts. Therefore, the same automated peak integration parameters as used before for wild-type extracts also were applied to the chromatograms in order to obtain a quantitative measure for the relative differences between the nodule extracts. In total, 21 wildtype nodule extracts were compared with 20 samples derived from either pseudonodules induced by Sm1021 exoY::Tn5 or nodules infected with Sm1021 nifH::Tn5.

Table 1. Differences in metabolic profiles of Medicago sativa nodules compared with roots ${ }^{\mathrm{a}}$

\begin{tabular}{|c|c|c|c|}
\hline Compound & Response ratio (nodule/root) & Compound & Response ratio (nodule/root) \\
\hline Amino acids & & Organic acids (Continued) & \\
\hline Maleic acid (245) & 2.5 & Glyceric acid $(189,192)$ & 3.4 \\
\hline 4-Aminobutyric acid (174) & 3.9 & Isocitric acid $(245,319)$ & 3.7 \\
\hline Alanine (116) & 11.1 & Lactic acid (191) & 4.8 \\
\hline Arginine (256) & 6.5 & Malic acid $(245,307)$ & 2.9 \\
\hline Aparagine (216) & 26.4 & Pantothenic acid (201) & 1.6 \\
\hline Aspartate (232) & 7.1 & Pyruvic acid (174) & 3.4 \\
\hline$\beta$-Alanine (248) & 4.2 & Shikimic acid (204) & 2.2 \\
\hline Cysteine (220) & 1.2 & Succinic acid $(247,409)$ & 13.2 \\
\hline Glutamine (155) & 30 & Sugars and polyols & \\
\hline Glutamate $(230,246)$ & 9.7 & Fructose (307) & 2.9 \\
\hline Glycine (174) & 6.5 & Glucose (319) & 1.1 \\
\hline Homoserine (218) & 2.9 & Gluconolactone (305) & 3.6 \\
\hline Isoleucine (158) & 10.6 & Maltose (361) & 1.4 \\
\hline Leucine (158) & 13.9 & $\mathrm{~m}_{y o-\text { Inositol (305) }}$ & 3.4 \\
\hline Lysine 156) & 11 & Pinitol (260) & 2.7 \\
\hline Methionine (176) & 5.8 & Ribose (217) & 3.2 \\
\hline \multirow{2}{*}{$\begin{array}{l}\text { Ornithine, arginine, } \\
\text { citrulline }(142)^{\mathrm{b}}\end{array}$} & & Sucrose (361) & 4.1 \\
\hline & 7.8 & Phosphates & \\
\hline Phenylalanine (192) & 5.5 & Erythrose-4-P (357) & 3.3 \\
\hline Proline (142) & 26.2 & Fructose-6-P (315) & 1.1 \\
\hline Serine (204) & 4.6 & Glucose-6-P (387) & 1.7 \\
\hline Threonine (101) & 6.1 & Glyceric acid-3-P $(227,299,459)$ & 3.5 \\
\hline Tyrosine (218) & 7.2 & Glycerol-3-P (357) & 3.7 \\
\hline Valine (144) & 11.3 & myo-Inositol-P (318) & 2.7 \\
\hline Organic acids & & Phosphoenolpyruvic acid (369) & 1.5 \\
\hline 2-Aminoadipic acid (260) & 11.7 & Ribose-5-P $(315,299)$ & 4.1 \\
\hline 2-Hydroxyglutaric acid & & $\mathrm{N}$-containing compounds & \\
\hline$(203,247)$ & 3 & Spermidine (144) & 8.8 \\
\hline 2-Ketoglutaric acid (198) & 5.7 & Urea (189) & 8 \\
\hline Methylcitric acid $(287)^{\mathrm{c}}$ & 75.9 & Purines-pyrimidines & \\
\hline Citric acid (257) & 3.6 & Adenine (264) & 4.4 \\
\hline Fumaric acid (245) & 13.7 & Adenosine (236) & 4.4 \\
\hline Gluconic acid (333) & 0.7 & Thymine ( 255) & 10.2 \\
\hline Glucuronic acid (333) & 2.3 & Uracil $(255,241)$ & 19.8 \\
\hline
\end{tabular}

${ }^{a}$ In order to compare differences in metabolite abundances between nodule and root tissues (21 samples each), the ratio of the mean normalized nodule data to the mean normalized root data was calculated. Ratios that are significantly different at $P<0.01$ ( $t$ test) are indicated in bold format; m/z values of selective ions used for quantification are shown in parentheses for each metabolite; $\mathrm{P}=$ phosphate.

${ }^{\mathrm{b}}$ Chemical interconversion of Arg and citrulline into Orn.

${ }^{\mathrm{c}}$ Mass spectrum highly similar to methylcitric acid identified in Lotus japonicus (Desbrosses et al. 2005). 
Hierarchical cluster analysis (HCA) and PCA of the obtained normalized data set could cluster the samples distinctly according to the three different nodule types. Interestingly, HCA showed that the samples extracted from wild-type and nifH nodules formed one subcluster, whereas the exoY nodule samples formed a discrete cluster. Thus, the metabolite profiles of wildtype and nifH nodules appear to be more similar to each other than to exoY nodules. Furthermore, HCA analyses of the three different nodule types and root extracts of plants nodulated by wild-type bacteria revealed that root samples formed a cluster that is separated from the nodule samples (data not shown).

The different multivariate data analysis tools applied were useful for generating a first global overview of the complex metabolite data set. Based on this first analysis, the data was investigated further in order to determine which metabolic features in particular distinguished wild-type nodules from noninfected and non-nitrogen-fixing nodules.

\section{Comparison of differences in the metabolite composition of $M$. sativa nodules induced by wild-type or mutant $S$. meliloti strains.}

The mean relative response ratios of the hydrophilic nodule extracts revealed several marked changes between wild-type nodules and both nodule types unable to fix atmospheric nitrogen (Table 2).

Bacteroid-free pseudonodules induced by Sm1021 exoY::Tn5 showed altered levels of many metabolites involved in carbon and nitrogen metabolism. In particular, several amino acids, including asparagine, glutamine, glutamate, alanine, and proline, showed a marked decrease in bacteroidfree nodules. In accordance with these reduced amino acid levels was the decreased amount of total protein in bacteroid-free nodules. Interestingly, the amino acid levels of isoleucine, methionine, serine, and leucine were elevated in pseudonodules compared with wild-type nodules. The abundances of all measured tricarboxylic acid (TCA) cycle intermediates were reduced significantly in nodules induced by Sm1021 exoY::Tn5. Furthermore, the metabolite pool of pyruvic acid was decreased in these nodules, whereas the glycolytic intermediates glyceric acid-3-P, fructose-6-P, and glucose-6-P remained unaltered. Similarly to the levels of glucose, fructose, and maltose, the amount of starch was significantly increased in pseudonodule extracts. This increase was in contrast to the reduced amount of sucrose levels in the uninfected nodules.

The extracts of nodules infected with the nitrogenase mutant of S. meliloti (Sm 1021 nifH::Tn5) revealed a marked number of metabolic differences compared with wild-type nodules. Most striking were the reduced amounts of asparagine and glutamine and the increased amount of pantothenic acid. Furthermore, the levels of the amino acids aspartate, alanine, and glutamate as well as the total protein content $(P=0.07)$ were reduced in these nodules. On the other hand, the amount of several other amino acids, including isoleucine, tyrosine, methionine, leucine, valine, and proline, were increased. Interestingly, the TCA cycle inter-
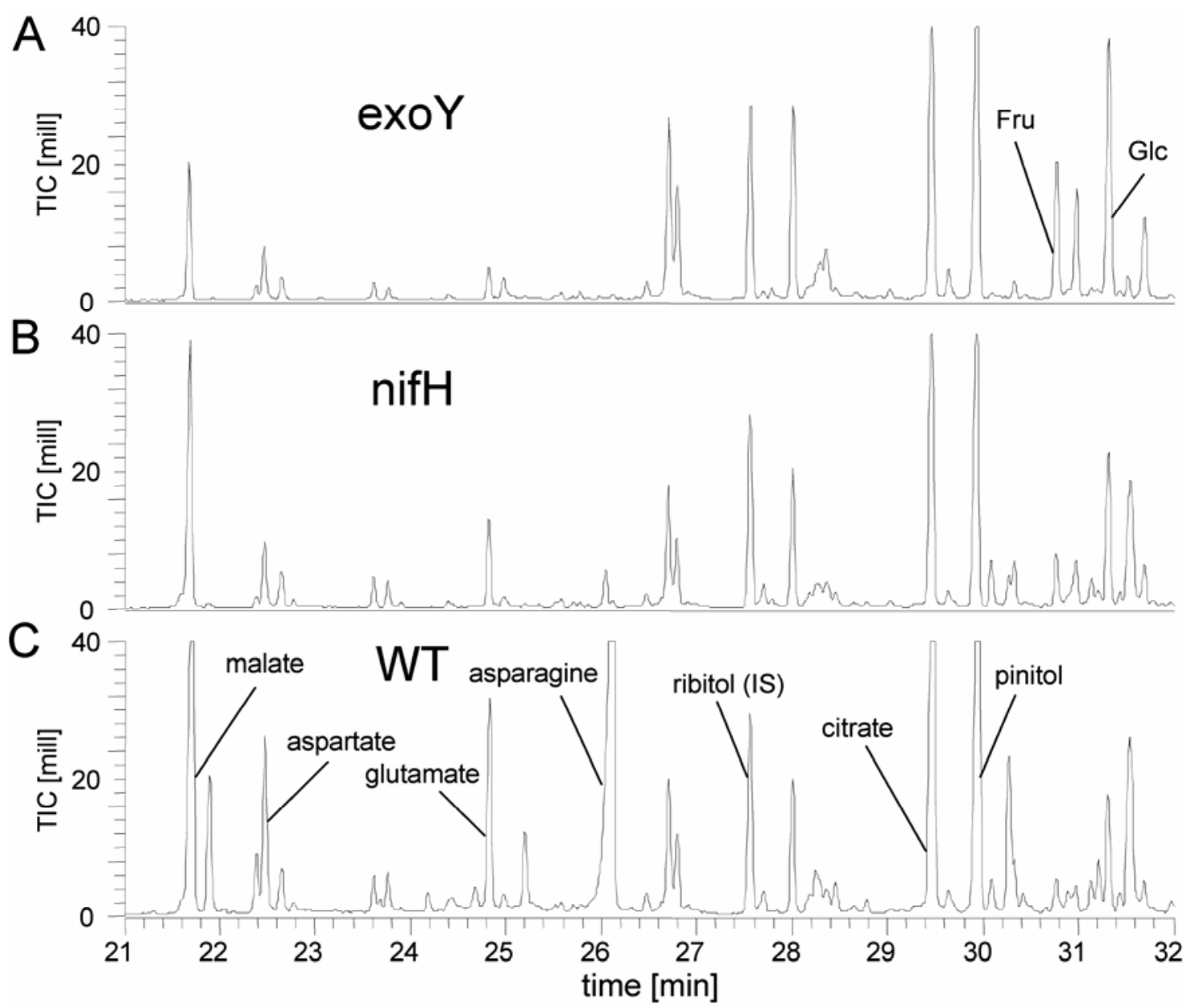

Fig. 1. Representative section of a typical gas chromatography-mass spectrometry total ion chromatogram of hydrophilic root nodule metabolites. Methanolic extracts were obtained from nodules induced by A, Sm1021 exoY::Tn5, B, Sm1021 nifH::Tn5, and C, wild-type (WT) Sm1021 Sinorhizobium meliloti strains. Several metabolites that are either equal in abundance or show marked differences between the extracts are indicated. IS $=$ internal standard and TIC $=$ total ion current. 
mediates isocitric acid, succinic acid, and 2-ketoglutaric acid showed no significant differences between wild-type and Fix nodules, whereas the levels of fumaric acid and malic acid were reduced significantly in nodules induced by $\mathrm{Sm} 1021$ nifH::Tn5. Several identified glycolytic intermediates, such as pyruvic acid and glyceric acid-3-P, were similarly abundant in both nodule types, whereas the amounts of glucose-6-P and fructose-6-P were slightly higher in the nitrogenase mutant nodules. Furthermore, glucose, fructose, maltose, and starch showed higher abundances in these nodules; however, the amount of sucrose was slightly higher in wild-type nodules.

In summary, nodules induced by infection (exoY) or fixation (nif $\mathrm{H})$ mutants of $S$. meliloti showed major alterations in the metabolic profiles when compared with wild-type nodules. The abundance of some identified metabolites appears to be altered specifically in either mutant and therefore, in total, might represent characteristic metabolic marker patterns for the two mutant nodule types.

\section{Nitrogen deficiency induced effects on $M$. sativa leaf metabolism.}

Growing plant leaves are major nitrogen sink tissues. Substantially reduced amounts of asparagine and glutamine observed in non-nitrogen-fixing nodules suggested that this decrease of the main transport form of fixed nitrogen in $M$. sativa might induce changes in leaf metabolism related to nitrogen limitation. Furthermore, because leaves of nodulated plants provide great amounts of photosynthates for the nitrogen-fixation process in nodules, changes in leaf carbohydrate metabolism are expected to compensate for the reduced carbon sink potential in nonfixing nodules. Therefore, some effects on leaf metabolism may be due to nitrogen limitation, whereas others may be the result of the interaction with the exo $\mathrm{Y}$ or nif $\mathrm{H}$ mutants of S. meliloti. In order to distinguish effects on leaf metabolism which are solely due to nitrogen limitation, leaves of non-nodulated plants were cultivated and compared with leaves of plants nodulated with wild-type or mutant S. meliloti strains (discussed above).

In total, 19 metabolite extracts derived from leaves harvested from plants nodulated by wild-type Sm1021 and 21 leaf samples of plants nodulated by Sm1021 nifH::Tn5, Sm1021 exoY::Tn5, or non-nodulated control plants were analyzed.

PCA analysis of the entire normalized data set obtained from the routinely quantified metabolites indicated that leaf samples derived from control plants and plants nodulated by wild-type $S$. meliloti 1021 formed separate clusters (data not shown). In contrast, leaf extracts of plants nodulated by either of the mutant $S$. meliloti strains could not be clearly separated.

Further investigation of the relative metabolite abundances revealed marked differences between the extracts of leaves derived from plants inoculated with wild-type bacteria and the extracts from non-nodulated control plants. Interestingly, many changes in metabolite levels observed in leaves of the control

Table 2. Metabolite levels of alfalfa nodules induced by Sm1021 (wild type), Sm1021 nifH::Tn5, and Sm1021 exoY::Tn5

\begin{tabular}{|c|c|c|c|}
\hline Compound & Wild type & nifH & exoY \\
\hline \multicolumn{4}{|l|}{ Amino acids } \\
\hline 4-Aminobutyric acid (174) & $1.00 \pm 0.10$ & $0.55 \pm 0.05$ & $0.47 \pm 0.05$ \\
\hline Alanine (116) & $1.00 \pm 0.10$ & $0.43 \pm 0.04$ & $\mathbf{0 . 2 2} \pm \mathbf{0 . 0 2}$ \\
\hline Arginine (256) & $1.00 \pm 0.16$ & $0.60 \pm 0.10$ & $\mathbf{0 . 4 5} \pm \mathbf{0 . 0 7}$ \\
\hline Asparagine (216) & $1.00 \pm 0.06$ & $0.09 \pm 0.01$ & $\mathbf{0 . 0 4} \pm \mathbf{0 . 0 0}$ \\
\hline Aspartate (232) & $1.00 \pm 0.07$ & $0.53 \pm 0.05$ & $\mathbf{0 . 4 3} \pm 0.04$ \\
\hline b-Alanine (248) & $1.00 \pm 0.06$ & $0.79 \pm 0.05$ & $\mathbf{0 . 6 8} \pm \mathbf{0 . 0 7}$ \\
\hline Cysteine (220) & $1.00 \pm 0.09$ & $1.58 \pm 0.22$ & $\mathbf{0 . 5 5} \pm \mathbf{0 . 0 7}$ \\
\hline Glutamine (155) & $1.00 \pm 0.10$ & $\mathbf{0 . 1 0} \pm \mathbf{0 . 0 2}$ & $\mathbf{0 . 1 1} \pm \mathbf{0 . 0 2}$ \\
\hline Glutamate $(230,246)$ & $1.00 \pm 0.05$ & $0.65 \pm 0.05$ & $\mathbf{0 . 2 5} \pm \mathbf{0 . 0 3}$ \\
\hline Glycine (174) & $1.00 \pm 0.06$ & $0.79 \pm 0.06$ & $\mathbf{0 . 4 5} \pm \mathbf{0 . 0 3}$ \\
\hline Homoserine (218) & $1.00 \pm 0.12$ & $1.66 \pm 0.20$ & $1.54 \pm 0.22$ \\
\hline Isoleucine (158) & $1.00 \pm 0.08$ & $3.51 \pm 0.25$ & $3.25 \pm 0.32$ \\
\hline Leucine (158) & $1.00 \pm 0.08$ & $2.88 \pm 0.23$ & $\mathbf{1 . 7 0} \pm \mathbf{0 . 1 9}$ \\
\hline Lysine (156) & $1.00 \pm 0.08$ & $1.19 \pm 0.10$ & $\mathbf{0 . 5 8} \pm \mathbf{0 . 0 9}$ \\
\hline Methionine (176) & $1.00 \pm 0.14$ & $3.00 \pm 0.57$ & $2.25 \pm 0.53$ \\
\hline Ornithine, arginine, citrulline (142) & $1.00 \pm 0.08$ & $0.69 \pm 0.03$ & $\mathbf{0 . 5 0} \pm \mathbf{0 . 0 5}$ \\
\hline Phenylalanine (192) & $1.00 \pm 0.06$ & $2.08 \pm 0.17$ & $0.82 \pm 0.11$ \\
\hline Proline (142) & $1.00 \pm 0.09$ & $2.02 \pm 0.22$ & $\mathbf{0 . 2 8} \pm \mathbf{0 . 0 4}$ \\
\hline Serine (204) & $1.00 \pm 0.07$ & $0.88 \pm 0.07$ & $1.97 \pm 0.18$ \\
\hline Threonine (101) & $1.00 \pm 0.05$ & $1.31 \pm 0.09$ & $0.82 \pm 0.07$ \\
\hline Tyrosine (218) & $1.00 \pm 0.07$ & $3.00 \pm 0.20$ & $\mathbf{0 . 5 4} \pm \mathbf{0 . 1 5}$ \\
\hline Valine (144) & $1.00 \pm 0.09$ & $\mathbf{2 . 0 3} \pm \mathbf{0 . 1 8}$ & $1.26 \pm 0.13$ \\
\hline Total protein $(\mu \mathrm{g} / \mathrm{mg} \mathrm{DW})$ & $58.58 \pm 4.45$ & $47.57 \pm 3.44$ & $37.33 \pm 4.34$ \\
\hline \multicolumn{4}{|l|}{ Organic acids } \\
\hline 2-Aminoadipic acid (260) & $1.00 \pm 0.16$ & $1.58 \pm 0.19$ & $\mathbf{0 . 4 5} \pm \mathbf{0 . 0 6}$ \\
\hline 2-Hydroxyglutaric acid $(203,247)$ & $1.00 \pm 0.06$ & $1.22 \pm 0.11$ & $\mathbf{0 . 2 8} \pm \mathbf{0 . 0 3}$ \\
\hline 2-Isopropylmalic acid (275) & $1.00 \pm 0.13$ & $0.99 \pm 0.15$ & $0.47 \pm \mathbf{0 . 1 1}$ \\
\hline 2-Ketoglutaric acid (198) & $1.00 \pm 0.09$ & $1.10 \pm 0.10$ & $\mathbf{0 . 5 3} \pm \mathbf{0 . 0 8}$ \\
\hline Methylcitric acid $(287)^{\mathrm{b}}$ & $1.00 \pm 0.06$ & $1.34 \pm 0.09$ & $\mathbf{0 . 0 5} \pm \mathbf{0 . 0 3}$ \\
\hline Citric acid (257) & $1.00 \pm 0.06$ & $0.83 \pm 0.05$ & $0.58 \pm 0.06$ \\
\hline Fumaric acid (245) & $1.00 \pm 0.06$ & $\mathbf{0 . 3 7} \pm \mathbf{0 . 0 2}$ & $\mathbf{0 . 0 5} \pm \mathbf{0 . 0 0}$ \\
\hline
\end{tabular}

\footnotetext{
${ }^{a}$ All data was normalized to the mean response of the wild-type nodules. Values presented correspond to the mean \pm standard error of 21 samples derived from wild-type nodules and 20 samples of nodules induced by Sm1021 nifH::Tn5 (nifH) and Sm1021 exoY::Tn5 (exoY), respectively. The total protein amount was determined from 10 nodule samples infected with Sm1021 and Sm1021 nifH::Tn5 and 9 nodule samples infected with Sm1021 exoY::Tn5. Values that were significantly different from wild-type samples are indicated in bold $(P<0.01) ; \mathrm{m} / \mathrm{z}$ values of selective ions used for quantification are shown in parentheses for each metabolite; DW = dry weight.

${ }^{\mathrm{b}}$ Mass spectrum highly similar to methylcitric acid identified in Lotus japonicus (Desbrosses et al. 2005).

${ }^{\mathrm{c}}$ Starch levels were determined by measuring the glucose amount after enzymatic degradation.
} 
plants likewise were detected in leaves of plants inoculated with the exoY or nifH mutant strains of $S$. meliloti.

The total amount of protein as well as the levels of most of the analyzed amino acids were decreased in the extracts of control and non-nitrogen-fixing plants compared with plants infected with the wild-type strain Sm1021. Levels of asparagine and glutamine were decreased especially, but the amounts of 4-aminobutyric acid, alanine, b-alanine, glutamate, homoserine, phenylalanine, proline, serine, and threonine also were signifycantly reduced in the leaves of all three nitrogen-starved plant types. Moreover, the amounts of fumaric acid, glyceric acid, shikimic acid, adenosine, uracil, and glycerol-3-P were reduced signifycantly in these extracts. In contrast, the levels of maltose, myoinositol, pinitol, and starch were increased in all the extracts compared with plants nodulated by wild-type rhizobia. Additionally, many metabolites were altered in the leaf extracts from all three nitrogen-starved plant types in a similar way; however, these observations were not always statistically significant.

Of special interest was the observation that some metabolites differed in their abundance between control plants and plants nodulated by the two different $S$. meliloti mutant strains. Leaves of nitrogen-starved control plants showed increased levels of fructose, glucose, sucrose, and tyrosine compared with plants nodulated by wild-type bacteria. In contrast, the amounts of fructose and glucose were significantly lower in plants nodulated by Sm1021 exo Y::Tn5 and the levels of sucrose and tyrosine were unchanged compared with leaf extracts of plants nodulated by Sm1021 wild type. None of these compounds were altered significantly in the extracts of alfalfa plants nodulated by Sm1021 nifH::Tn5. Furthermore, the levels of citric acid, isocitric acid, 2-ketoglutaric acid, and succinic acid were significantly increased in leaf extracts of plants nodulated by the exoY::Tn5 or nifH::Tn5 mutant strains of $S$. meliloti. However, these metabolites showed similar abundances in nonnodulated control plants and plants infected with wild-type Sm1021.

The amounts of cysteine and pantothenic acid were increased in leaves of plants nodulated by the nif $\mathrm{H}:: \operatorname{Tn} 5$ mutant $S$. meliloti strain, whereas cysteine levels were not significantly altered and pantothenic acid levels were decreased in control plants and plants nodulated by Sm1021 exoY::Tn5. Of special interest were markedly reduced levels of spermidine in leaves of plants nodulated by either mutant $S$. meliloti strain, whereas similar amounts were detected in leaves of plants nodulated by wildtype bacteria and control plants. The rationale behind this surprising metabolic phenotype remains to be elucidated.

Metabolic profiles of leaves harvested from the plants in different symbiotic situations indicated several characteristic metabolites corresponding to nitrogen limitation. Furthermore, alterations in plants nodulated by exo $\mathrm{Y}$ or nifH mutants of $S$. meliloti provided metabolic evidence related to a noneffective symbiotic interaction.

\section{Gene expression profiles of nodules induced} by nifH::Tn5 mutant and wild-type $S$. meliloti strains.

Transcriptional changes in both symbiotic partners were analyzed by comparing wild-type nodules and nodules induced by $\mathrm{Sm}$ nifH::Tn5. Analysis of four biological replicates re-

Table 2. (Continued from preceding page)

\begin{tabular}{|c|c|c|c|}
\hline Compound & Wild type & nifH & exoY \\
\hline \multicolumn{4}{|l|}{ Organic acids (Continued) } \\
\hline Gluconic acid (333) & $1.00 \pm 0.06$ & $1.02 \pm 0.07$ & $\mathbf{0 . 7 7} \pm \mathbf{0 . 0 5}$ \\
\hline Glucuronic acid (333) & $1.00 \pm 0.13$ & $0.86 \pm 0.12$ & $1.40 \pm 0.19$ \\
\hline Glyceric acid $(189,192)$ & $1.00 \pm 0.04$ & $0.91 \pm 0.06$ & $\mathbf{0 . 6 6} \pm \mathbf{0 . 0 3}$ \\
\hline Isocitric acid $(245,319)$ & $1.00 \pm 0.05$ & $0.85 \pm 0.06$ & $\mathbf{0 . 6 5} \pm \mathbf{0 . 0 6}$ \\
\hline Lactic acid (191) & $1.00 \pm 0.10$ & $0.85 \pm 0.08$ & $0.91 \pm 0.09$ \\
\hline Maleic acid (245) & $1.00 \pm 0.18$ & $1.05 \pm 0.15$ & $0.56 \pm 0.11$ \\
\hline Malic acid $(245,307)$ & $1.00 \pm 0.07$ & $0.71 \pm \mathbf{0 . 0 3}$ & $\mathbf{0 . 2 4} \pm \mathbf{0 . 0 2}$ \\
\hline Pantothenic acid (201) & $1.00 \pm 0.06$ & $4.58 \pm 0.33$ & $\mathbf{0 . 2 8} \pm \mathbf{0 . 1 4}$ \\
\hline Pyruvic acid (174) & $1.00 \pm 0.05$ & $1.07 \pm 0.10$ & $\mathbf{0 . 6 9} \pm \mathbf{0 . 0 5}$ \\
\hline Shikimic acid (204) & $1.00 \pm 0.05$ & $0.41 \pm 0.03$ & $\mathbf{0 . 3 0} \pm \mathbf{0 . 0 2}$ \\
\hline Succinic acid $(247,409)$ & $1.00 \pm 0.06$ & $0.91 \pm 0.05$ & $\mathbf{0 . 3 9} \pm \mathbf{0 . 0 3}$ \\
\hline \multicolumn{4}{|l|}{ Sugars and polyols } \\
\hline Fructose (307) & $1.00 \pm 0.15$ & $1.66 \pm 0.12$ & $3.16 \pm 0.43$ \\
\hline Glucose (319) & $1.00 \pm 0.06$ & $1.57 \pm 0.11$ & $1.76 \pm 0.14$ \\
\hline Gluconolactone (305) & $1.00 \pm 0.06$ & $1.29 \pm 0.13$ & $0.52 \pm 0.05$ \\
\hline Maltose (361) & $1.00 \pm 0.07$ & $2.76 \pm 0.30$ & $2.50 \pm 0.33$ \\
\hline myo-Inositol (305) & $1.00 \pm 0.05$ & $1.77 \pm 0.12$ & $0.92 \pm 0.07$ \\
\hline Pinitol (260) & $1.00 \pm 0.05$ & $0.93 \pm 0.07$ & $0.44 \pm 0.03$ \\
\hline Ribose (217) & $1.00 \pm 0.06$ & $1.23 \pm 0.09$ & $1.00 \pm 0.08$ \\
\hline Sucrose (361) & $1.00 \pm 0.08$ & $0.75 \pm 0.12$ & $0.66 \pm 0.05$ \\
\hline $\operatorname{Starch}(\mathrm{Glc})^{\mathrm{c}}$ & $1.00 \pm 0.13$ & $2.38 \pm 0.21$ & $2.60 \pm 0.17$ \\
\hline \multicolumn{4}{|l|}{ Phosphates } \\
\hline Erythrose-4-P (357) & $1.00 \pm 0.22$ & $0.76 \pm 0.16$ & $0.98 \pm 0.17$ \\
\hline Fructose-6-P (315) & $1.00 \pm 0.06$ & $1.41 \pm 0.16$ & $0.97 \pm 0.10$ \\
\hline Glucose-6-P (387) & $1.00 \pm 0.06$ & $1.26 \pm 0.13$ & $0.80 \pm 0.09$ \\
\hline Glyceric acid-3-P $(227,299,459)$ & $1.00 \pm 0.12$ & $1.11 \pm 0.12$ & $0.84 \pm 0.11$ \\
\hline Glycerol-3-P (357) & $1.00 \pm 0.05$ & $1.15 \pm 0.08$ & $0.57 \pm 0.04$ \\
\hline myo-Inositol-P (318) & $1.00 \pm 0.05$ & $0.91 \pm 0.04$ & $0.59 \pm 0.03$ \\
\hline Phosphoenolpyruvic acid (369) & $1.00 \pm 0.20$ & $1.12 \pm 0.28$ & $1.17 \pm 0.26$ \\
\hline Ribose-5-P $(315,299)$ & $1.00 \pm 0.10$ & $1.01 \pm 0.06$ & $0.52 \pm 0.05$ \\
\hline \multicolumn{4}{|l|}{$\mathrm{N}$-containing compounds } \\
\hline Spermidine (144) & $1.00 \pm 0.19$ & $0.61 \pm 0.12$ & $0.19 \pm 0.05$ \\
\hline Urea (189) & $1.00 \pm 0.18$ & $0.54 \pm 0.11$ & $0.59 \pm 0.11$ \\
\hline \multicolumn{4}{|l|}{ Purines-pyrimidines } \\
\hline Adenine (264) & $1.00 \pm 0.15$ & $1.15 \pm 0.18$ & $0.54 \pm 0.10$ \\
\hline Adenosine (236) & $1.00 \pm 0.06$ & $1.09 \pm 0.09$ & $0.18 \pm 0.02$ \\
\hline Thymine (255) & $1.00 \pm 0.08$ & $1.21 \pm 0.22$ & $0.70 \pm 0.08$ \\
\hline Uracil $(255,241)$ & $1.00 \pm 0.08$ & $0.73 \pm 0.09$ & $0.49 \pm 0.04$ \\
\hline
\end{tabular}


vealed that 35 genes were differentially expressed $(P<0.05)$ at least 1.5 -fold in the microsymbiont, which corresponded to 17 repressed and 18 induced genes within the mutant nodules. In contrast, a total of $117 \mathrm{M}$. sativa genes were at least 1.8 -fold differentially expressed $(P<0.05)$, comprising transcripts of 83 genes that were lower abundant and 34 with higher levels in nifH mutant nodules.

In particular, $S$. meliloti genes with a significantly reduced expression in nif $\mathrm{H}$ mutant nodules (Table 3) included the nifD, $n i f \mathrm{~K}$, and nif $\mathrm{N}$ genes, which are known to be cotranscribed with the nifH gene (Barnett et al. 1998). Furthermore, the nif X, Sma0833, $f d x \mathrm{~B}$, orf10.5, and syrA genes located downstream of the nifHDKE operon, as well as several transcripts of genes encoding putative transport proteins (i.e., sit $\mathrm{D}$, liv $\mathrm{G}, \operatorname{chr} \mathrm{A}$, and $c c m \mathrm{~A})$, were less abundant in nifH mutant nodules. In contrast, several nod and nif transcripts were more abundant in these nodules. Of special interest were the observations of an increased level of the SMc02596 transcript encoding a putative LysR-like transcriptional regulator protein and of the proB 2 gene encoding a putative glutamate-5-kinase involved in proline biosynthesis.

Several gene products of the macrosymbiont $M$. sativa in volved in carbon and nitrogen metabolism were expressed at lower levels in mutant nodules induced by $\mathrm{Sm}$ nifH::Tn5. These genes encoded asparagine synthetase, glutamate synthase, phosphoenolpyruvate carboxylase, sucrose synthase, gibberellin-2-oxidase, and a putative pyrophosphate-dependent phosphofucto-1-kinase (Table 3). In contrast, transcripts of genes encoding a glucose-1-phosphate adenylyltransferase and a trehalose-6-phosphate phosphatase were more abundant in mutant nodules. Interestingly, elevated transcript levels of several genes encoding proteinases, in particular cysteine proteinases, were detected in nif $\mathrm{H}$ mutant nodules, whereas two proteinase inhibitor gene transcripts were less abundant.

In order to validate the differential expression of $M$. sativa genes recorded on $M$. truncatula oligonucleotide microarrays, real-time reverse transcriptase-polymerase chain reaction (RT-

Table 3. Differences in gene expression profiles of Medicago sativa nodules induced by Sinorhizobium meliloti 1021 nifH::Tn5 compared with wild-type (WT) nodules induced by $\mathrm{Sm} 1021^{\mathrm{a}}$

\begin{tabular}{|c|c|c|c|}
\hline Gene ID & Gene description & $\begin{array}{c}\text { Microarray } \log 2 \text { ratio } \\
\text { nifH/WT nodule }\end{array}$ & $\begin{array}{l}\text { RT-PCR log2 ratio } \\
\text { nifH/WT nodule }\end{array}$ \\
\hline \multicolumn{4}{|c|}{ S. meliloti genes } \\
\hline SMa0772 & nodL NodL Nod factor acetyltransferase & 1.08 & $\ldots$ \\
\hline SMa0774 & noeB NoeB host-specific nodulation protein & 0.96 & $\ldots$ \\
\hline SMc02596 & Putative transcriptional regulator protein & 0.96 & $\ldots$ \\
\hline SMa0814 & nifB NifB FeMo cofactor biosynthesis protein & 0.89 & $\ldots$ \\
\hline SMa0811 & fdxN FdxN ferredoxin & 0.79 & $\ldots$ \\
\hline SMc03252 & proB2 putative glutamate 5 kinase protein & 0.67 & $\ldots$ \\
\hline SMc02506 & sitD Manganese $\mathrm{ABC}$ transporter permease & -0.80 & $\ldots$ \\
\hline \multirow[t]{2}{*}{ SMc01949 } & livG probable high-affinity branched chain amino acid transport & & \\
\hline & ATP-binding ABC transporter protein & -0.81 & $\ldots$ \\
\hline SMc00808 & chrA putative chromate transport protein & -0.84 & $\ldots$ \\
\hline SMa0834 & fdxB FdxB ferredoxin III & -0.84 & $\ldots$ \\
\hline SMb21510 & Putative plasmid stability protein & -0.84 & $\ldots$ \\
\hline SMa0835 & orf10.5 hypothetical $10.5-\mathrm{kDa}$ open reading frame & -0.87 & $\ldots$ \\
\hline SMa0830 & nifE NifE oxidoreductase & -0.90 & $\ldots$ \\
\hline SMc03847 & ccmA putative heme exporter $\mathrm{A}$ & -1.11 & $\ldots$ \\
\hline SMa0827 & nifD NifD nitrogenase Fe Mo alpha chain & -1.87 & $\ldots$ \\
\hline SMa0838 & syrA SyrA protein involved in exopolysaccharide production & -1.88 & $\ldots$ \\
\hline SMa0806 & Probable SyrB-like regulator & -1.92 & $\ldots$ \\
\hline SMa0831 & nifX NifX nitrogen fixation protein & -2.02 & $\ldots$ \\
\hline SMa0829 & nifK NifK nitrogenase Fe Mo beta chain & -3.87 & $\ldots$ \\
\hline \multicolumn{4}{|c|}{ M. sativa genes } \\
\hline TC85915 & Cysteine proteinase & 3.96 & 9.73 \\
\hline TC78139 & Cysteine proteinase & 3.59 & 5.52 \\
\hline TC85913 & Cysteine proteinase & 3.53 & $\ldots$ \\
\hline TC78485 & Probable carboxypeptidase $\mathrm{C}$ & 2.32 & 4.64 \\
\hline TC85911 & Cysteine proteinase & 2.13 & $\ldots$ \\
\hline TC81601 & Cysteine protease & 1.98 & $\ldots$ \\
\hline TC83332 & Cysteine protease & 1.46 & $\ldots$ \\
\hline TC81584 & Putative NADH dehydrogenase & 1.04 & $\ldots$ \\
\hline TC83374 & Glucose-1-phosphate adenylyltransferase & 0.96 & 1.95 \\
\hline TC78537 & Trehalose-6-phosphate phosphatase & 0.90 & 1.17 \\
\hline TC83644 & Aspartic proteinase delta & 0.90 & $\ldots$ \\
\hline TC77574 & Putative pyrophosphate-dependent phosphofructo-1-kinase & -0.82 & $\ldots$ \\
\hline TC77553 & NADH-dependent glutamate synthase & -0.94 & $\ldots$ \\
\hline TC78351 & Phosphoenolpyruvate carboxylase & -0.96 & $\ldots$ \\
\hline TC85400 & Sucrose synthase & -0.96 & -1.17 \\
\hline TC86329 & Subtilisin-like proteinase & -1.02 & $\ldots$ \\
\hline BE187546 & Phosphoenolpyruvate carboxylase & -1.13 & $\ldots$ \\
\hline TC90692 & Gibberellin 2-oxidase & -1.14 & $\ldots$ \\
\hline TC88042 & Phosphoenolpyruvate carboxylase kinase & -1.14 & -1.60 \\
\hline BQ157772 & Proteinase inhibitor & -1.27 & $\ldots$ \\
\hline TC85436 & Asparagine synthetase & -2.11 & $\ldots$ \\
\hline BQ157772 & Proteinase inhibitor & -2.36 & $\ldots$ \\
\hline TC87888 & Serine carboxypeptidase & -2.36 & -3.04 \\
\hline TC93637 & NADH-dependent glutamate synthase & -2.73 & -2.49 \\
\hline TC85437 & Asparagine synthetase & -2.75 & -3.16 \\
\hline
\end{tabular}

${ }^{\text {a }}$ Selected genes differentially expressed in nif $\mathrm{H}$ mutant nodules compared with WT nodules as determined by microarray and real-time reverse-transcriptase polymerase chain reaction (RT-PCR; values shown are significantly different at $P<0.05, n=6$ ). 
PCR) experiments were performed for several genes covering a range of expression ratios. Based on three biological replicates, the analysis of five up- and five downregulated genes confirmed the differential expression in nifH mutant compared with wild-type nodules (Table 3 ). As reported earlier (Hohnjec et al. 2005), several expression ratios determined by real-time RT-PCR were higher than the corresponding values obtained by microarray hybridizations.

\section{DISCUSSION}

\section{Metabolite profiles}

of nitrogen-starved alfalfa leaves reveal global changes in carbon and nitrogen metabolism and indicate compounds potentially involved in nitrogen status sensing.

Maintenance of plant nitrogen homeostasis is based on matching $\mathrm{N}$ uptake and assimilation to $\mathrm{N}$ demands. Sensing the current nitrogen status potentially takes place in plant shoots, allowing the integration of nitrogen supply irrespective of the actual nitrogen source (e.g., nitrate, ammonium, or atmospheric nitrogen fixation) (Parsons and Sunley 2001). Signals sent back to the root systems and nodules might regulate nitrogen acquisition by feedback mechanisms, although the identity of potential signals remains still unknown.

Therefore, it was interesting to analyze metabolic changes in the leaves of different nitrogen-starved alfalfa plants compared with plants nodulated by wild-type $S$. meliloti. In general, many of the determined changes were observed similarly within nitrogen-starved control plants and plants nodulated by the different mutants of $S$. meliloti unable to provide symbiotically fixed nitrogen.

Thus, it was not unexpected to determine lower levels of protein as well as amino acids in leaves of the different nitrogen-starved alfalfa plants compared with plants nodulated by wild-type rhizobia. Previous studies determined lower amino acid and protein levels in nitrogen-starved leaves (Paul and Driscoll 1997; Scheible et al. 1997) supporting these observations. Accumulation of starch in all nitrogen-starved leaves indicates excess carbon and metabolically suggests that carbohydrate demand or export cannot keep up with photosynthesis in all of these plants (Dennis and Blakeley 2000). Furthermore, nitrogen deprivation previously was shown to cause starch accumulation in plants and assumed to be a passive response to decreased growth rates (Paul and Driscoll 1997; Scheible et al. 2004; Stitt and Krapp 1999). Increased amounts of sucrose, glucose, and fructose in non-nodulated nitrogen-starved control plants similarly were observed in nitrogen-starved tobacco plants (Nielsen et al. 1998; Paul and Driscoll 1997). Interestingly, this contradicted lower or unchanged levels of these carbohydrates in plants nodulated by either mutant $S$. meliloti strain. This observation might be related to a higher export of carbohydrates in order to enable nodule growth, whereas this carbon sink is absent in non-nodulated plants.

Of special interest was the increased amount of pantothenic acid, a precursor for Coenzyme A (CoA) biosynthesis, in leaves of plants nodulated by the S. meliloti nifH::Tn5 mutant. However, it is difficult to elucidate metabolic significance of this observation due to the lack of a comprehensive method to profile CoA and its esters (Broeckling et al. 2005) and the number of enzymatic reactions involving CoA (Kanehisa et al. 2006).

Surprisingly, noneffective symbioses led to a substantially decreased amount of the $\mathrm{N}$-rich metabolite spermidine in leaves. N-rich compounds, such as arginine and citrulline, were discussed to be involved in $\mathrm{N}$ status sensing (Parsons and Sunley 2001), suggesting a potential role for spermidine in sensing of nitrogen deficiency caused by the lack of nitrogen provision by the mutant $S$. meliloti strains. Furthermore, Parsons and Sunley (2001) highlighted the fact that sensing of the nitrogen status might involve measurement of a "nitrogen charge," corresponding to the ratio of glutamine, glutamate, and 2-ketoglutaric acid $(1 / 2[2(\mathrm{Gln})+(\mathrm{Glu})] /[(\mathrm{Gln})+(\mathrm{Glu})+(2$-ketoglu $)])$ in accordance with the cellular adenylate charge introduced by (Atkinson 1968). Decreased levels of glutamine and glutamate in the leaves of nitrogen-starved plants and increased amounts of 2-ketoglutaric acid in plants nodulated by the mutant bacteria imply a drastic decrease in this nitrogen charge that might relate to the sensing of nitrogen starvation.

In summary, metabolite profiles of different nitrogen-starved alfalfa leaves revealed many alterations in carbon and nitrogen metabolism that could be supported by numerous studies reported earlier. Interestingly, in contrast to previous approaches, the nontargeted analysis of hydrophilic metabolites highlighted several metabolites (like spermidine) potentially involved in sensing of the global nitrogen status and in recognition of an inefficient association with root symbionts.

\section{Comparison of nodule and root metabolite compositions indicate characteristic metabolites for $M$. sativa nodules.}

Hydrophilic metabolite extracts of $M$. sativa roots and nodules analyzed by GC-MS were compared to determine compounds characteristic for nodule metabolism. In general, it was reassuring to determine higher levels of several glycolytic and all analyzed citric acid cycle intermediates (Fig. 2). It is generally accepted that legume plants fuel bacteroid nitrogen fixation by dicarboxylic acids synthesized via glycolytic degradation of sucrose to PEP and conversion to malate by PEP carboxylase (Kahn et al. 1998).

Because nodules serve as the main $\mathrm{N}$ source tissue of nodulated legume plants, elevated levels of nearly all identified amino acid pools and corresponding biosynthetic precursors such as shikimate were indicative of an elevated amino acid biosynthesis in root nodules (Fig. 2). Furthermore, high nodule/root ratios of asparagine and glutamine are conclusive with alfalfa nodules exporting fixed nitrogen mainly as amides (Kahn et al. 1998).

High levels of proline have been postulated to be indicative of nodules being subject to osmotic stress (Colebatch et al. 2004; Desbrosses et al. 2005) and this is further substantiated by elevated amounts of pinitol, another potential osmoprotectant, and its biosynthetic precursors myo-inositol-P and myo-inositol.

The elevated amount of 4-aminobutyrate in nodules provides metabolic evidence for the activity of the 4-aminobutyrate shunt which bypasses the 2-oxoglutarate dehydrogenase reaction in the TCA cycle. This is substantiated by transcriptomic and proteomic studies (Becker et al. 2004; Djordjevic 2004) which indicated that succinic semialdehyde dehydrogenase involved in the 4-aminobutyrate shunt is present in $S$. meliloti bacteroids.

Of further striking difference were elevated levels of thymine and uracil in root nodules, implying their importance for nodule metabolism. The hypothesis that high amounts of uracil indicate increased RNA turnover is not substantiated by transcriptomic evidence (Becker et al. 2004). Nevertheless, during nodule organogenesis more than 750 genes are differentially expressed in $M$. truncatula, implying significant RNA metabolism (El Yahyaoui et al. 2004).

The high level of a putative methylcitric acid detected in nodules indicates an important role for this metabolite in alfalfa nodules. Because high mass spectral similarity to a methylcitric acid also has been described for L. japonicus nodules (Desbrosses et al. 2005), this metabolite might be of general importance for legume nodules. Although the exact position of the methyl group in the methylcitric acid is not completely resolved, comparison of retention time and mass spectra of purified 2-methyl- 
citric acid and 2-methylisocitric acid excluded both as possible candidates. Therefore, the only possible isomers of methylcitric acid are 3-methylisocitric acid and 4-methylisocitric acid, highlighting them as the most likely candidates for this metabolite. A possible pathway for the synthesis of 4-methylcitric acid might be similar to the methylcitric acid cycle described for bacteria (Claes et al. 2002). Dehydration of 2-methylcitric acid with double bond formation between the carbon atoms 3 and 4 and subsequent hydration with hydroxylation in position 2 will form 4 methylcitric acid. Nevertheless, because both compounds are not commercially available, explicit identification of this interesting compound and elucidation of the corresponding biochemical pathway will rely on chemical synthesis.

In summary, the presented metabolite data illustrated the activity and importance of several biochemical pathways, including glycolysis and amino acid biosynthesis, in alfalfa root nodules. Furthermore, several metabolites, including proline, 2-aminoadipic acid, and methylcitric acid, were shown to be likewise enhanced in L. japonicus nodules (Desbrosses et al. 2005), indicating that these compounds might be of general importance for root nodule metabolism. Future work will have to address the special relevance of these metabolites and integrate them into the present knowledge of nodule physiology.

Metabolic profiles of nodules induced

by $S$. meliloti exoY::Tn5 (Fix $\left.{ }^{-}\right)$mutant bacteria reveal interesting metabolic features

at early stages of the symbiotic interaction.

Several lines of evidence indicate that nodule development requires signals that define transcriptionally distinct stages
(Mitra and Long 2004; Vance and Gantt 1992; Vance et al. 1994). Such transcriptionally distinct stages likely are accompanied by appropriate physiological changes in both symbiotic partners. However, indeterminate nodules contain bacteroids of different developmental stages; therefore, a direct access to study metabolic transitions by separating plant and bacteroid fractions is error prone (Ampe et al. 2003). Furthermore, dissecting bacteroid and plant metabolism might be accompanied by unintended changes rendering the interpretation of the results impossible (Lodwig and Poole 2003). Therefore, we compared metabolite profiles derived from entire nodules induced by $\mathrm{Sm}$ exoY::Tn5 ( Inf $^{-}$) or $\mathrm{Sm}$ nif $\mathrm{H}:: \operatorname{Tn} 5$ (Fix $\left.{ }^{-}\right)$mutants with wildtype nodules. Developmental mutants proved valuable in order to dissect the complex plant bacterial interactions (Ampe et al. 2003; Lodwig et al. 2003; Mitra and Long 2004). In principle, initial nodule organogenesis seems to establish, to some extent, the biochemical environment required for active nitrogen fixation, although total activation of all the related processes (i.e., dicarboxylate production and ammonia assimilation) depend on an effective symbiotic interaction (Vance et al. 1994). Therefore, bacteroid-free pseudonodules might provide important information on metabolic processes induced during early developmental stages of nodulation.

Increased amounts of starch as well as maltose, glucose, and fructose in bacteroid-free nodules (Fig. 3A) are in agreement with microscopic evidence of starch accumulation in nodules induced by Sm exoY::Tn5 mutants (Müller et al. 1988; Niehaus et al. 1993). Because storage of starch generally is interpreted as excess of carbohydrates (Vance and Heichel 1991), the lack of ammonium supply seems not to entirely eliminate carbon

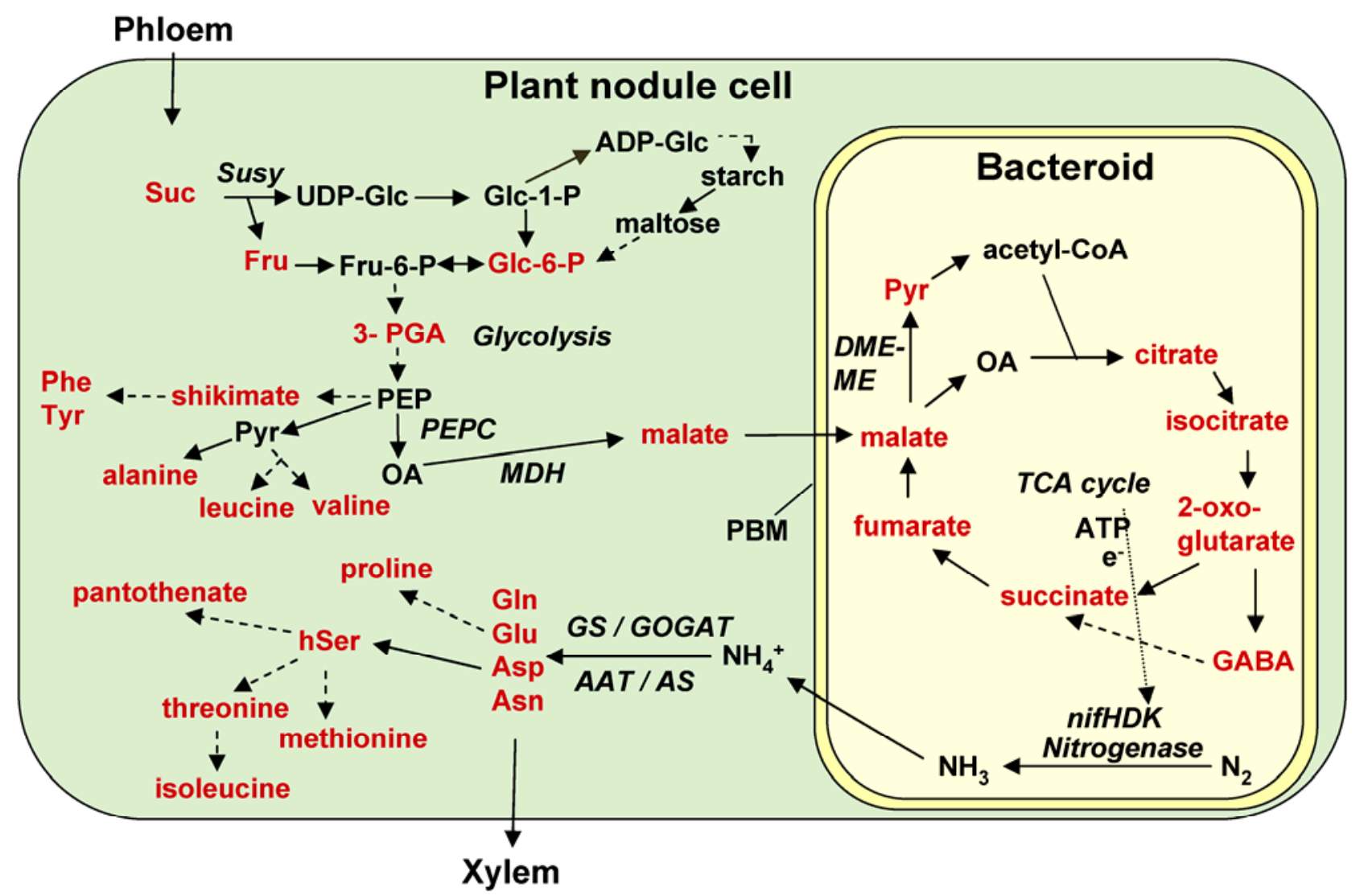

Fig. 2. Schematic representation of nodule metabolism. Metabolites marked in red were significantly higher in nodules compared with roots. AAT, aspartate aminotransferase; AS, asparagine synthetase; Asn, asparagine; Asp, aspartate; hSer, homoserine; MDH, malate dehydrogenase; DME-ME, NAD-dependent malic enzyme; Fru, fructose; GABA, 4-amino butyric acid; Glc, glucose; Gln, glutamine; Glu, glutamate; GOGAT, glutamate synthase; GS, glutamine synthetase; OA, oxaloacetate; PBM, peribacteroid membrane; PEPC, phosphoenolpyruvate carboxylase; 3-PGA, glyceric acid 3-P; Phe, phenylalanine; Pyr, pyruvic acid; Suc, sucrose; Susy, sucrose synthase; Tyr, tyrosine. 

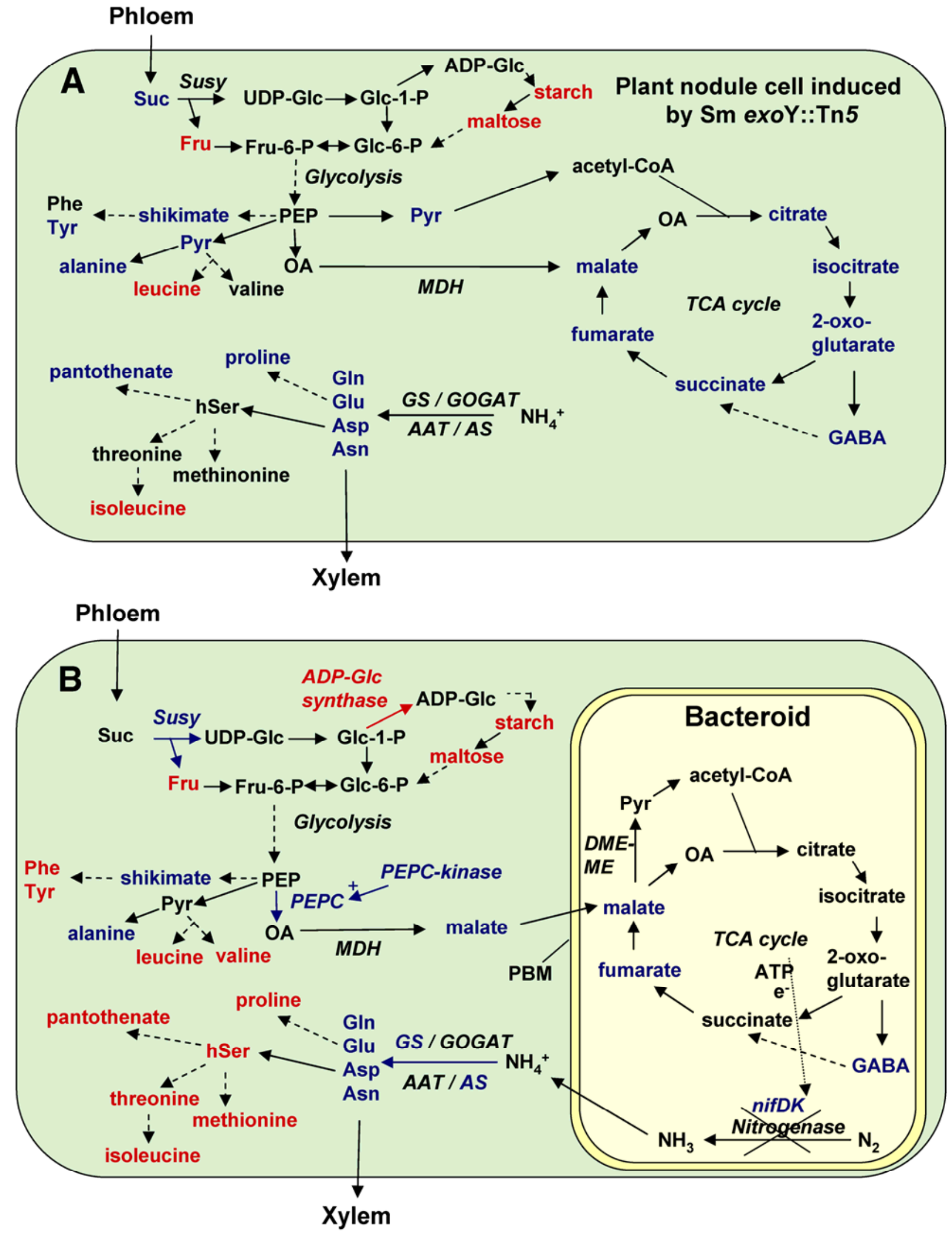

Fig. 3. Schematic representation of metabolism in nodules induced by $\mathbf{A}, \mathrm{Sm} 1021$ exoY::Tn 5 and $\mathbf{B}, \mathrm{Sm} 1021$ nifH::Tn5. Metabolites and gene transcripts marked in red were significantly induced in mutant compared with wild-type nodule extracts, whereas those highlighted in blue were decreased. AAT, aspartate aminotransferase; AS, asparagine synthetase; Asn, asparagine; Asp, aspartate; hSer, homoserine; MDH, malate dehydrogenase; DME-ME, NAD-dependent malic enzyme; Fru, fructose; GABA, 4-amino butyric acid; Glc, glucose; Gln, glutamine; Glu, glutamate; GOGAT, glutamate synthase; GS, glutamine synthetase; OA, oxaloacetate; PBM, peribacteroid membrane; PEPC, phosphoenolpyruvate carboxylase; Phe, phenylalanine; Pyr, pyruvic acid; Suc, sucrose; Susy, sucrose synthase; Tyr, tyrosine. 
supply to root nodules. Furthermore, this indicates that the primary processes of nodule formation involve the allocation of carbohydrates to the new plant organs. This would be in agreement with the hypothesis that spontaneous nodules are modified carbon-storage organs (Schultze and Kondorosi 1998).

In contrast to elevated levels of carbohydrates, all measured TCA cycle intermediates were reduced in nodules induced by Sm exoY::Tn5. This observation proves that carbohydrates are supplied to pseudonodules but the massive formation of dicarboxylic acids is not induced to a similar extent as in wild-type nodules. It has been shown that nodules induced by $S$. meliloti exo Y::Tn5 do not contain an $\mathrm{O}_{2}$ diffusion barrier (Masepohl et al. 1993). $\mathrm{C}_{4}$-dicarboxylic acid formation previously was described to be an adaptation to low $\mathrm{O}_{2}$ concentrations in nodule tissues; therefore, reduced levels of these compounds probably are correlated directly to higher $\mathrm{O}_{2}$ concentrations.

The marked reduction of most amino acid levels in pseudonodules is in general accordance with the lack of ammonium provision. Of special interest were significantly increased amounts of isoleucine, leucine, and serine in pseudonodule extracts, although the physiological relevance of this observation cannot be estimated based on sole metabolite pool data. In principle, reduced levels of proline in nodules induced by $\mathrm{Sm}$ exoY::Tn5 might be based on the lack of nitrogen fixation. Nevertheless, similarly reduced amounts of myo-inositol-P and pinitol could indicate that their role as osmoprotectants is required only in the presence of bacteroids.

\section{Metabolic and gene expression profiles of nodules induced by $\mathrm{Sm}$ nifH::Tn5 $\left(\mathrm{Fix}^{-}\right)$reveal interesting features prior to the onset of nitrogen fixation.}

$S$. meliloti fixation mutants lacking the nitrogenase protein complex cannot provide ammonium to the host plants. Therefore, it was not unexpected to determine several similar metabolic alterations as seen in pseudonodules induced by $\mathrm{Sm}$ exoY::Tn5. Presumably, many of these changes are directly related to the lack of ammonium provision. Nevertheless, previous microscopic analyses of both nodule types revealed morphological and histological differences indicating that the presence of non-nitrogen-fixing bacteroids is accompanied by specific metabolic alterations.

For a number of metabolites, it is very challenging to interpret specific aspects of the observed physiological changes in whole organs such as nodules, which consist of the two symbiotic partners, solely with metabolomic approaches because of the difficulty to unambiguously determine the origin of a specific metabolite. Therefore, determining changes in gene expression by microarray experiments was very helpful in discriminating between influences on nodule metabolism originating from the plant or bacterial side.

Interestingly, only a minor fraction of plant and bacterial genes were differentially expressed in nodules induced by $\mathrm{Sm}$ nifH::Tn5 compared with wild-type nodules. Previous results of less than $1 \%$ differentially expressed genes in ineffective nodules on sen 1 mutants of $L$. japonicus substantiated this observation (Suganuma et al. 2004). Furthermore, this is in principle agreement to an earlier observation that most upregulated genes in wild-type $M$. truncatula nodules also were induced in non-nitrogen-fixing nodules induced by $S$. meliloti 1021 fix $^{-}$ (Barnett et al. 2004). In contrast, very few bacterial transcripts of nodules induced by $S$. meliloti $1021 \mathrm{fix}^{-} \mathrm{J}^{-}$were found to increase compared with wild-type nodules (Barnett et al. 2004). This obvious discrepancy to our data might be explained by the fact that the FixLJ two-component regulatory system mediates the oxygen-dependent expression of a variety of nif and fix gene expressions via FixK and NifA (Kaminski et al. 1998). Therefore, minor transcriptional changes in nodules induced by $\mathrm{Sm}$ nifH::Tn5 compared with wild-type nodules do not substantiate the hypothesis that most bacterial gene induction in nodules correlates with the ability to fix nitrogen (Barnett et al. 2004). In principle, this indicates, transcriptionally, that the analyzed non-nitrogen-fixing nodules, for the most part, resemble wild-type nodules.

Genes with a lower transcript level in mutant nodules comprise eight genes located downstream of the nifH gene (i.e., $n i f \mathrm{D}, n i f \mathrm{~K}, n i f \mathrm{~N}, n i f \mathrm{X}, \mathrm{SMa} 0833, f d x \mathrm{~B}$, orf10.5, and $s y r \mathrm{~A})$. Most likely, this is due to a polar effect of the $\operatorname{Tn} 5$ insertion into the nif $\mathrm{H}$ gene, because expression of the syrA gene in the symbiotic state previously was proposed to occur via a transcriptional readthrough from the nif promoter (Barnett et al. 1998). Lower transcript abundances of several genes encoding transport proteins might be related to reduced metabolic activity in nitrogenase mutant bacteroids. Increased transcriptional abundance of the nod $\mathrm{L}$ and adjacent genes in these nodules indicates a further role of NodL in addition to involvement in Nod factor biosynthesis, as previously hypothesized (Barnett et al. 2004).

Lower total protein amounts in nodules induced by $S$. meliloti nifH mutants might be due to a lack of ammonium supply and a reduced metabolic activity, as previously hypothesized (Rosendahl et al. 1990). Nevertheless, increased transcript levels of several plant cysteine proteinases in nifH mutant nodules might imply a potential role of protein turnover in order to recycle nitrogen. Furthermore, elevated transcript levels of cysteine proteinases as well as increased enzyme activities have been reported earlier for noneffective nodules and suggested to be the result of premature senescence (Pladys and Vance 1993; Suganuma et al. 2004). Reduced levels of shikimate, a precursor of phenylalanine and tyrosine biosynthesis, most likely is indicative of a decreased aromatic amino acid biosynthesis, whereas increased levels of several amino acids, including isoleucine, leucine, methionine, phenylalanine, threonine, tyrosine, and valine, further substantiate a general role of protein degradation in noneffective nodules (Fig. 3B). Nevertheless, increased branched chain amino acids previously were reported in elicited $M$. truncatula cell cultures and correlated to increased secondary metabolism (e.g., isoprenoid biosynthesis instead of protein degradation; discussed below) (Broeckling et al. 2005). Clearly decreased levels of asparagine and glutamine in both mutant nodule types metabolically highlight the importance of amides as transport metabolites for fixed nitrogen in alfalfa. Aspartate and glutamate are involved in the primary ammonium fixation process and synthesis of asparagine in nodules (Vance and Gantt 1992); therefore, reduced amounts of both amino acids were anticipated. Furthermore, reduced transcript levels of asparagine synthetases and glutamate synthases substantiate this observation and are in agreement with previous observations (Rosendahl et al. 1990).

The observed high levels of starch in nitrogenase mutant nodules are in agreement with microscopic observations of starch grains in nifH mutant nodules (Hirsch et al. 1983). Elevated levels of a glucose-1-P adenylyltransferase transcript indicate increased starch biosynthesis because the encoded enzyme is involved in ADP-glucose formation required for starch formation. Higher levels of starch, glucose, fructose, and maltose are in agreement with the hypothesis that carbohydrate allocation to uninfected or noneffective nodules is not the primary plant sanction in maintaining a balanced symbiotic interaction.

The dependence of organic acid synthesis in root nodules upon $\mathrm{NH}_{4}^{+}$availability was discussed previously (Vance and Gantt 1992). Reduced transcript levels of characteristic enzymes involved in nodule carbon metabolism (e.g., sucrose synthase, PEPC, and PEPC-kinase) in noneffective nodules suggest the 
involvement of ammonium as well as other related signals in nodule gene expression. Our results confirm reduced amounts of malic and fumaric acid in both mutant nodule types. Furthermore, this indicates that synthesis of the dicarboxylic acids is not exclusively related to reduced nodule $\mathrm{O}_{2}$ levels which might shunt plant glycolysis to malate as suggested for nodules induced by Sm exoY::Tn5. The pink color of nifH nodules and no significant changes in transcript levels of leghemoglobin genes strongly indicates the presence of leghemoglobin and thus, in principle, the existence of low $\mathrm{O}_{2}$ levels; therefore, further regulations must be involved in reduced dicarboxylic acid levels in these nodules.

An important role of proline, tyrosine, pantothenic acid, and methylcitric acid for nodule metabolism is implied by decreased amounts in bacteroid-free compared with higher amounts in nitrogenase-deficient nodules. High amounts of proline in infected nodules are indicative of osmotic stress. Higher transcript abundance of the bacterial proB2 gene in nodules induced by $\mathrm{Sm}$ nif $\mathrm{H}: \mathrm{Tn} 5$ encoding a putative glutamate-5-kinase involved in proline biosynthesis suggests a bacterial origin for this metabolite. Because pantothenic acid is a precursor for CoA biosynthesis, increased amounts in nodules induced by nitrogenase-deficient bacteria indicate changes in metabolism involving CoA. Many different metabolites exist as CoA conjugates and, like acetyl-CoA, can be involved in diverse metabolic reactions. It was tempting to speculate on an influence on fatty acid metabolism relying on acetyl-CoA and malonyl-CoA. Nevertheless, visual inspection of fatty acid profiles derived from total fatty acid extracts of wild-type or nitrogenase mutant nodules did not reveal marked differences. Interestingly, elevated levels of branched chain amino acids and $\beta$-alanine, a precursor in CoA-biosynthesis, previously were determined in biotically stressed M. truncatula cell cultures. These changes were proposed to indicate an altered metabolism of CoA and its esters in order to provide carbon for secondary metabolism (Broeckling et al. 2005). Nevertheless, lower transcript levels of 3-hydroxy-3-methylglutaryl-CoA reductase and chalcone reductase observed in $n i f H$ mutant nodules that are involved in isoprenoid and flavonoid biosynthesis, respectively, may indicate a reduced carbon flow into secondary metabolism. A putative methylcitric acid derivative is of special interest because it appears to be characteristic for bacteroid containing nodules because it is abundant in wild-type and nitrogenfixation-deficient nodules but barely detectable in bacteroidfree nodules. The metabolic function or the originating pathway for this metabolite in the S. meliloti-Medicago spp. symbiosis is still elusive; however, a similar metabolite has been described in nodules of $L$. japonicus. This implies that this compound is involved in general nodule metabolism; however, this needs further investigation. It would be especially interesting to determine whether methylcitric acid is of plant or bacterial origin.

Interestingly, transcriptional abundance of a serine carboxypeptidase was much lower in nodules induced by Sm nifH::Tn5. This is further substantiated by a similarly determined repression of a serine carboxypeptidase in noneffective L. japonicus nodules (Suganuma et al. 2004). Furthermore, it could be shown that the corresponding gene is induced during nodule organogenesis (Starker et al. 2006), implying an involvement in nitrogen-fixation capacity, although the exact role of this protein remains unclear.

\section{Conclusion.}

The symbiotic interaction of $S$. meliloti and $M$. sativa is based on alternating control of both partners during nodule development. Recent studies indicated the existence of transcrip- tionally discrete checkpoints during nodule organogenesis (Barnett et al. 2004; Mitra and Long 2004), although the signals mediating these potential checkpoints still remain unknown.

Bacterial and plant mutants arrested at different developmental steps are well-established tools to characterize these potential checkpoints. Due to the complex interaction, nodules arrested at different stages of development might show secondary physiological adaptations not directly related to nodule organogenesis. Nevertheless, metabolic profiles indicated that nodules induced by Sm exoY::Tn5 triggered the formation of a new carbon sink organ but no massive organic acid formation as in wild-type nodules.

Of special interest were the limited transcriptional differences between wild-type and nif $\mathrm{H}$ mutant bacteroids in contrast to several changes in plant gene transcripts. These suggest that mutant nodules induced by $\mathrm{Sm} 1021$ nifH::Tn5 are arrested at a checkpoint primarily controlled by the macrosymbiont. This hypothesis is substantiated by both metabolic and transcriptional data, indicating reduced dicarboxylic acid formation. Furthermore, transcriptional induction of several cysteine proteinases might be in direct correlation to early senescence previously observed in $\mathrm{Fix}^{-}$nodules and the determined increase in amino acid levels. In summary, these data indicate a loss of autonomy in regulation for the microsymbiont. This could be caused by the fact that the physiological environment and environmental signals before the onset of nitrogen fixation are widely controlled by the host plant. Nevertheless, as recently shown, amino acid cycling between both symbionts is required for nitrogen fixation, preventing the symbiosis from being dominated by the plant at later stages of interaction (Lodwig et al. 2003). In accordance to the proposed role of alanine for amino acid cycling, levels were decreased in nifH mutant nodules similarly to levels of asparagine, aspartate, glutamine, and glutamate involved in primary steps of ammonium assimilation.

On a global scale, the metabolic data revealed that bacteroid nitrogen fixation is required for the adjustment of carbon and nitrogen source and sink tissues, which is reflected by differences in the metabolic composition in the respective plant leaves. Indicated metabolites might be involved in regulatory processes, although further experiments are required to dissect the specific functions of theses compounds in leaf and root nodule physiology.

\section{MATERIALS AND METHODS}

\section{Plant material.}

Alfalfa seed (M. sativa L. cv. Du Puits; obtained from S. Kruse, Bielefeld, Germany) were surface sterilized by stirring $5 \mathrm{~min}$ in $32 \% \mathrm{HCl}$ and rinsing three times with sterile water. Agar plates for nodulation were prepared as previously described (Rolfe et al. 1980), with modifications. All solutions were autoclaved separately $\left(\mathrm{A}: \mathrm{CaCl}_{2} \times 2 \mathrm{H}_{2} \mathrm{O}\right.$ at 294 $\mathrm{g} /$ liter [wt/vol]; $\mathrm{B}+\mathrm{B}_{1}: \mathrm{K}_{2} \mathrm{HPO}_{4}$ at $150 \mathrm{~g} /$ liter [wt/vol] and $\mathrm{KH}_{2} \mathrm{PO}_{4}$ at $50 \mathrm{~g} / \mathrm{liter}$ [wt/vol]; $\mathrm{B}_{1}: \mathrm{K}_{2} \mathrm{HPO}_{4}$ at $116 \mathrm{~g} / \mathrm{liter}$ [wt/vol]; C: Fe-citrate at $6.7 \mathrm{~g} /$ liter [wt/vol]; $\mathrm{D}: \mathrm{MgSO}_{4} \times 7$ $\mathrm{H}_{2} \mathrm{O}$ at $123 \mathrm{~g} /$ liter [wt/vol], $\mathrm{K}_{2} \mathrm{SO}_{4}$ at $87 \mathrm{~g} /$ liter [wt/vol], $\mathrm{MnSO}_{4} \times \mathrm{H}_{2} \mathrm{O}$ at $0.338 \mathrm{~g} / \mathrm{liter}$ [wt/vol], $\mathrm{H}_{3} \mathrm{BO}_{3}$ at 0.247 g/liter [wt/vol], $\mathrm{ZnSO}_{4} \times 7 \mathrm{H}_{2} \mathrm{O}$ at $0.288 \mathrm{~g} /$ liter [wt/vol], $\mathrm{CuSO}_{4} \times 5 \mathrm{H}_{2} \mathrm{O}$ at $0.1 \mathrm{~g} /$ liter [wt/vol], $\mathrm{CoSO}_{4} \times 7 \mathrm{H}_{2} \mathrm{O}$ at $0.056 \mathrm{~g} /$ liter [wt/vol], and $\mathrm{Na}_{2} \mathrm{MoO}_{4} \times 2 \mathrm{H}_{2} \mathrm{O}$ at $0.048 \mathrm{~g} / \mathrm{liter}$ [wt/vol]). Solutions of $\mathrm{A}, \mathrm{B}+\mathrm{B}_{1}, \mathrm{C}$, and $\mathrm{D}$ at $0.5 \mathrm{ml} / \mathrm{liter}$ (vol/vol) and solution $B_{1}$ at $1.0 \mathrm{ml} /$ liter ( $\left.\mathrm{vol} / \mathrm{vol}\right)$ were added to 1 liter of sterilized water containing plant agar (Duchefa, Haarlem, The Netherlands) at $18 \mathrm{~g} / \mathrm{liter}$ (wt/vol). Seed were germinated for 2 days on agar plates in the dark. Subsequently, four seedlings were transferred per nodulation plate 
and inoculated with $50 \mu \mathrm{l}$ of a stationary phase $S$. meliloti suspension culture, whereas control plants remained uninoculated. Plants were cultivated in a growth chamber at $24^{\circ} \mathrm{C}$ with a photoperiod consisting of $16 \mathrm{~h}$ of light and $8 \mathrm{~h}$ of dark and a light intensity of $80 \mu \mathrm{mol}$ photons $\mathrm{m}^{-2} \mathrm{~s}^{-1}$.

\section{Bacterial strains.}

The wild-type $S$. meliloti strain used in the present study was Sm1021 (Galibert et al. 2001). Furthermore, two $S$. meliloti 1021 mutant strains carrying a transposon Tn5 in the exo $\mathrm{Y}\left(\mathrm{EPS}^{-}\right)$and the nifH $\left(\mathrm{Fix}^{-}\right)$gene were used for plant inoculation. In order to generate these mutants, the Tn5-containing regions of Rm0540 (Sm2011 exoY::Tn5) (Müller et al. 1988) and Sm2011 nifH::Tn5 (provided by A. Becker, Dept. of Genetics, Bielefeld University, Germany) were transduced into S. meliloti 1021 by phage $\Phi$ M12 (Finan et al. 1984). Localization of the Tn5 after transduction was confirmed by sequencing the genomic regions adjacent to the transposon (Becker et al. 1997). S. meliloti cells were cultured aerobically at $30^{\circ} \mathrm{C}$ in tryptone-yeast medium (Beringer 1974) supplemented as required with streptomycin at $600 \mu \mathrm{g} / \mathrm{ml}$ (wild type) or neomycin at $120 \mu \mathrm{g} / \mathrm{ml}$ (Tn5 mutants).

\section{Harvesting of plant material \\ for metabolite and protein analysis.}

Plants inoculated with S. meliloti 1021, S. meliloti 1021 exoY::Tn5, and S. meliloti 1021 nif $\mathrm{H}:: \mathrm{Tn} 5$, plus control plants, were analyzed $21 \mathrm{dpi}$. Uniform populations of 14 agar plates containing four plants each were sampled per experiment. Nodules, leaves, and primary roots (several centimeters of the main root directly below the hypocotyl) were harvested in the middle of the light cycle and immediately frozen in liquid nitrogen. Biological material from two plates was pooled in order to obtain enough material for metabolite analysis. The entire experiment was replicated three times, resulting in 21 samples (with few exceptions) for each tissue and inoculation type analyzed (three sets of seven samples, each consisting of material pooled from eight plants.

\section{Acetylene reduction.}

Acetylene reduction was performed as previously described (Rolfe et al. 1980).

\section{Metabolite extraction.}

Metabolites were extracted as previously described (Barsch et al. 2004). After adding $0.5 \mathrm{~g}$ of zirconia glass beads (ROTH, Karlsruhe, Germany) to the lyophilized samples, metabolites were extracted with $1 \mathrm{ml}$ of $80 \%$ methanol containing $10 \mu \mathrm{M}$ ribitol as internal standard in a FastPrep Instrument (Qbiogene, Heidelberg, Germany). Tissues were disrupted four times at $6.5 \mathrm{~m} / \mathrm{s}$ for $45 \mathrm{~s}$. Metabolite extraction was improved by incubation at $70^{\circ} \mathrm{C}$ for $15 \mathrm{~min}$ at $1,400 \mathrm{rpm}$ in a Thermomixer (Eppendorf, Hamburg, Germany). After 20 min of centrifugation at $13,000 \mathrm{rpm}$ at room temperature, the clear supernatant was transferred to 1-ml glass vials (Supelco, Bellefonte, PA, U.S.A.) and evaporated in a nitrogen stream. Metabolites were derivatized with $50 \mu$ l of methoxylamine hydrochloride in pyridine $(20 \mathrm{mg} / \mathrm{ml}$; wt/vol) for $90 \mathrm{~min}$ at $37^{\circ} \mathrm{C}$ and $50 \mu \mathrm{l}$ of $N$-methyl- $N$-trimethylsilyltrifluoroacetamide for $30 \mathrm{~min}$ at $37^{\circ} \mathrm{C}$.

\section{GC-MS analysis.}

Sample volumes of $1 \mu \mathrm{l}$ were analyzed with a TraceGC gas chromatograph coupled to a PolarisQ ion trap mass spectrometer equipped with an AS2000 auto sampler (Thermo Electron, Dreieich, Germany). Derivatized metabolites were evaporated at $250^{\circ} \mathrm{C}$ in splitless mode and separated on a 30-m-by-0.25- mm Equity-5 column with $0.25-\mu \mathrm{m}$ coating (Supelco, Bellafonte, PA, U.S.A.). Helium carrier gas flow was adjusted to 1 $\mathrm{ml} / \mathrm{min}$. The interface and ion source temperatures were set to 250 and $200^{\circ} \mathrm{C}$, respectively. Oven temperature was kept constant for $3 \mathrm{~min}$ at $80^{\circ} \mathrm{C}$ and subsequently raised to $325^{\circ} \mathrm{C}$ at $5^{\circ} \mathrm{C} / \mathrm{min}$. The system was equilibrated for $5 \mathrm{~min}$ at $80^{\circ} \mathrm{C}$ after each analysis. Metabolites were identified by comparison with purified standards and the NIST 98 database (NIST, Gaithersburg, MD, U.S.A.). In addition, the freely available Golm Metabolome Database (Kopka et al. 2005) was of particular help in identifying several metabolites. Selected metabolite peak areas were quantified automatically using the processing setup implemented in the Xcalibur software (version 1.4; Thermo Electron).

\section{Data normalization.}

Relative response ratios were calculated by normalizing the respective peak areas to the peak area of the internal standard and dividing the value by the dry weight of the extracted sample. It is important to notice that GC-MS tuning parameters can vary over time and hamper a comparison of datasets measured at different times (Roessner et al. 2001). Extracts of different tissues and biological replicates were measured at different days; therefore, two different normalization methods were used for normalizing root-to-nodule and wild-type-tomutant nodule data sets, respectively.

Data for root versus nodule comparisons were normalized by dividing the relative response ratios by the mean relative response of both tissue types (i.e., nodule and root). Furthermore, the mean relative response ratios of nodules and roots used for calculating the nodule/root ratios are shown.

In order to generate normalized relative response ratios for the comparison of different nodule types, the data set of each biological replicate was normalized to the corresponding extracts of wild-type nodules as a reference (Roessner et al. 2001). Therefore, the average relative response ratios for the metabolites of the reference samples (wild-type nodules) were calculated and all relative response ratios of the analyzed replicate were divided by the corresponding values.

\section{Starch determination.}

Starch was determined principally as previously described (MacRae 1971). Eight leaf and nodule samples derived from two different biological replicates were analyzed. The residues of the metabolite extractions were washed three more times with $1 \mathrm{ml}$ of $100 \%$ methanol. Dried pellets were incubated with $200 \mu \mathrm{l}$ of $0.5 \mathrm{M} \mathrm{NaOH}$ at $60^{\circ} \mathrm{C}$ for $1 \mathrm{~h}$ and subsequently neutralized with $200 \mu \mathrm{l}$ of $0.5 \mathrm{M} \mathrm{HCl}$. Starch was digested enzymatically overnight at $37^{\circ} \mathrm{C}$ by adding $70 \mu \mathrm{l}$ of amyloglucosidase (Roche, Mannheim, Germany) and $530 \mu \mathrm{l}$ of $0.2 \mathrm{M}$ $\mathrm{NaAc}, \mathrm{pH}$ 4.5. Following heat inactivation of amyloglucosidase at $99^{\circ} \mathrm{C}$ for $5 \mathrm{~min}$, the relative amount of glucose in the supernatant was determined after derivatization by GC-MS.

\section{Extraction and determination of total protein.}

For total protein determination, nodules and leaves were harvested from plants of two biological replicates. For each biological replicate, five samples were analyzed, containing a plant material dry weight of 4 to $6 \mathrm{mg}$ for leaf and 0.4 to $1 \mathrm{mg}$ for nodule samples. After addition of $0.5 \mathrm{~g}$ of zirconia glass beads (ROTH) and $1 \mathrm{ml}$ of phosphate-buffered saline containing protease inhibitor (complete EDTA-free; Roche, Mannheim, Germany), proteins were extracted using a FastPrep Instrument (Qbiogene, Heidelberg, Germany). Samples were extracted four times at $6.5 \mathrm{~m} / \mathrm{s}$ for $45 \mathrm{~s}$. Between extraction steps, samples were cooled on ice for $1 \mathrm{~min}$. Samples were centrifuged at $13,000 \mathrm{rpm}$ at $4^{\circ} \mathrm{C}$ and 50 to $75 \mu \mathrm{l}$ of the supernatant 
was used for determining the total protein content using a Bradford Assay (Biorad, München, Germany), each sample consisting of three technical replicates.

\section{Microarray analysis and real-time RT-PCR experiments.}

Microarray analysis was performed using Sm6kOligo (Krol and Becker 2004) and Mt16kOLI1Plus microarrays. Microarray Mt16kOLI1Plus is based on Mt16kOLI1 microarrays described by Hohnjec and associates (2005) but carries an additional set of 384 oligonucleotides.

Total RNA was extracted from four biological replicates per nodule type ( 30 plates containing five plants each were harvested 21 dpi per replicate) using TRI reagent (Sigma) and purified using Microcon-30 columns (Millipore, Schwalbach, Germany). RNA $(20 \mu \mathrm{g})$ was used to synthesize Cy3- and Cy5-labeled cDNA. Labeling of hybridization targets, hybridization image acquisition, and analysis of image data were carried out as described by Hohnjec and associates (2005) and Krol and Becker (2004). Data files were analyzed using the EMMA software (Dondrup et al. 2003). Lowess normalization was performed using a floor value of 20 and student's $t$ test was applied to identify differentially expressed genes. Furthermore, significantly regulated genes had to meet the following conditions: $P \leq 0.05, N \geq 5$, and $A \geq 5.5$.

Genes of interest were selected from the data sets by keyword search in the annotations and the current TC denominations were retrieved from the TIGR Medicago gene index (release 8.0, January 2005).

Real-time RT-PCR experiments were performed in two technical replicates in accordance with a protocol reported by Hohnjec and associates (2003), with total RNA extracted from three biological replicates per nodule type. RNA was prepared using in-solution DNaseI digestion according to the manufacturer's instructions (Qiagen, Hilden, Germany) and subsequent concentration via Microcon-30 (Millipore, Schwalbach, Germany) columns.

The following gene-specific primers were used for real-time RT-PCR: TC85437, ATTGTGATGTTATTGCACACT, and TGCTAGAGTACAAATGACCAG; TC85400, CTGAGGAAA GCTGAAGAGTAT, and GACATCATCTTGAGCAAAGTA; TC85915, ATGCTAGTGGATCTGACTTTC, and CAGTTTG CTCAAATTACAAAG; TC78139, ATGAGAATTTTACCAA AGCTC, and GGGTAATAGCTTTCTGTTGTT; TC78537, ACTCATGTCAAATCTTCTCCT, and CTATGCATCTTCCA GTAACAA; TC88042, GTCTTAGAGCTTTGTCAACCT, and TCTCTTCCTAATAGAACCTCC; TC93637, CTCAATTGAT TCACGATCTTA, and ATCTCTTCCGGTTTTTAGTT; TC78485, ATCTAAAGGGTTTTGCTATTG, and GTCATAA CAAAGACTTCCCTC; TC87888, GATCAAGCAGTTGATG AAGTA, and TGCAAATACTCCAATTCTTTA; TC83374, AACGTTCACTGTTTGGATTA, and CATTAAAATTGTGAT TCCTGA; TC106470(Tef $\alpha)$, AATGTTAAGAATGTTGCTG TG, and AACCATCTTAATGATACCAGC.

\section{Chemicals.}

Chemicals and standard compounds were purchased from Sigma-Aldrich-Fluka (Taufkirchen, Germany), Merck (Darmstadt, Germany) or Macherey-Nagel (Düren, Germany).

\section{Cluster and statistical analysis.}

In order to determine statistical significance $(P<0.01)$ the $t$ test algorithm of Excel 2003 (Microsoft, Seattle, WA, U.S.A.) was performed. PCA and HCA were performed with the Pirouette software (version 3.02; Infometrix, Woodinville, WA, U.S.A.). HCA has the primary purpose to visualize complex data sets in a way that highlights natural groupings. Similarities in HCA dendrograms can be assessed by the value of the connection distance between two samples, with a value of 1 being most similar. For HCA, the data was $\log _{10}$ transformed and Euclidean distance was used to calculate the matrix of all samples (Roessner et al. 2001). PCA allows clustering of samples based on an $n$-dimensional vector approach that identifies and ranks sources of variance within complex data sets. PCA was performed with $\log _{10}$-transformed data and cross validation (Fiehn et al. 2000).

\section{ACKNOWLEDGMENTS}

W. Buckel and D. Darley are gratefully acknowledged for their gift of 2-methylisocitrate and A. Becker is acknowledged for providing the $S$. meliloti microarrays. A. Barsch received a grant from the International NRW Graduate School in Bioinformatics and Genome Research.

\section{LITERATURE CITED}

Ampe, F., Kiss, E., Sabourdy, F., and Batut, J. 2003. Transcriptome analysis of Sinorhizobium meliloti during symbiosis. Genome Biol. 4:R15.

Atkinson, D. E. 1968. The energy charge of the adenylate pool as a regulatory parameter. Interaction with feedback modifiers. Biochemistry 7:4030-4034.

Barnett, M. J., Swanson, J. A., and Long, S. R. 1998. Multiple genetic controls on Rhizobium meliloti syrA, a regulator of exopolysaccharide abundance. Genetics 148:19-32.

Barnett, M. J., Toman, C. J., Fisher, R. F., and Long, S. R. 2004. A dualgenome Symbiosis Chip for coordinate study of signal exchange and development in a prokaryote-host interaction. Proc. Natl. Acad. Sci. U.S.A. 101:16636-16641.

Barsch, A., Patschkowski, T., and Niehaus, K. 2004. Comprehensive metabolite profiling of Sinorhizobium meliloti using gas chromatographymass spectrometry. Funct. Integr. Genomics 4:219-230.

Becker, A., Berges, H., Krol, E., Bruand, C., Ruberg, S., Capela, D., Lauber, E., Meilhoc, E., Ampe, F., de Bruijn, F. J., Fourment, J., Francez-Charlot, A., Kahn, D., Kuster, H., Liebe, C., Puhler, A., Weidner, S., and Batut, J. 2004. Global changes in gene expression in Sinorhizobium meliloti 1021 under microoxic and symbiotic conditions. Mol. Plant-Microbe Interact. 17:292-303.

Becker, A., Ruberg, S., Kuster, H., Roxlau, A. A., Keller, M., Ivashina, T., Cheng, H. P., Walker, G. C., and Puhler, A. 1997. The 32-kilobase exp gene cluster of Rhizobium meliloti directing the biosynthesis of galactoglucan: Genetic organization and properties of the encoded gene products. J. Bacteriol. 179:1375-1384.

Beringer, J. E. 1974. R factor transfer in Rhizobium leguminosarum. J. Gen. Microbiol. 84:188-198.

Broeckling, C. D., Huhman, D. V., Farag, M. A., Smith, J. T., May, G. D., Mendes, P., Dixon, R. A., and Sumner, L. W. 2005. metabolite profiling of Medicago truncatula cell cultures reveals the effects of biotic and abiotic elicitors on metabolism. J. Exp. Bot. 56:323-336.

Cheng, H. P., and Walker, G. C. 1998. Succinoglycan is required for initiation and elongation of infection threads during nodulation of alfalfa by Rhizobium meliloti. J. Bacteriol. 180:5183-5191.

Claes, W. A., Puhler, A., and Kalinowski, J. 2002. Identification of two prpDBC gene clusters in Corynebacterium glutamicum and their involvement in propionate degradation via the 2-methylcitrate cycle. J. Bacteriol. 184:2728-2739.

Colebatch, G., Desbrosses, G., Ott, T., Krusell, L., Montanari, O., Kloska, S., Kopka, J., and Udvardi, M. K. 2004. Global changes in transcription orchestrate metabolic differentiation during symbiotic nitrogen fixation in Lotus japonicus. Plant J. 39:487-512.

Cook, D. R. 1999. Medicago truncatula-a model in the making! Curr. Opin. Plant Biol. 2:301-304.

Dennis, D. T., and Blakeley, S. D. 2000. Carbohydrate metabolism In: Biochemistry \& Molecular Biology of Plants. B. B. Buchanan, W. Gruissem, and R. L. Jones, eds. American Society of Plant Physiologists, Rockville, MD, U.S.A.

Desbrosses, G. G., Kopka, J., and Udvardi, M. K. 2005. Lotus japonicus metabolic profiling. Development of gas chromatography-mass spectrometry resources for the study of plant-microbe interactions. Plant Physiol. 137:1302-1318.

Djordjevic, M. A. 2004. Sinorhizobium meliloti metabolism in the root nodule: A proteomic perspective. Proteomics 4:1859-1872.

Dondrup, M., Goesmann, A., Bartels, D., Kalinowski, J., Krause, L., Linke, B., Rupp, O., Sczyrba, A., Puhler, A., and Meyer, F. 2003. EMMA: A platform for consistent storage and efficient analysis of microarray data. J. Biotechnol. 106:135-146. 
El Yahyaoui, F., Kuster, H., Ben Amor, B., Hohnjec, N., Puhler, A., Becker, A., Gouzy, J., Vernie, T., Gough, C., Niebel, A., Godiard, L., and Gamas, P. 2004. Expression profiling in Medicago truncatula identifies more than 750 genes differentially expressed during nodulation, including many potential regulators of the symbiotic program. Plant Physiol. 136:3159-3176.

Fiehn, O., Kopka, J., Dormann, P., Altmann, T., Trethewey, R. N., and Willmitzer, L. 2000. Metabolite profiling for plant functional genomics. Nat. Biotechnol. 18:1157-1161.

Finan, T. M., Hartweig, E., LeMieux, K., Bergman, K., Walker, G. C., and Signer, E. R. 1984. General transduction in Rhizobium meliloti. J. Bacteriol. 159:120-124.

Galibert, F., Finan, T. M., Long, S. R., Puhler, A., Abola, P., Ampe, F., Barloy-Hubler, F., Barnett, M. J., Becker, A., Boistard, P., Bothe, G. Boutry, M., Bowser, L., Buhrmester, J., Cadieu, E., Capela, D., Chain, P., Cowie, A., Davis, R. W., Dreano, S., Federspiel, N. A., Fisher, R. F. Gloux, S., Godrie, T., Goffeau, A., Golding, B., Gouzy, J., Gurjal, M., Hernandez-Lucas, I., Hong, A., Huizar, L., Hyman, R. W., Jones, T., Kahn, D., Kahn, M. L., Kalman, S., Keating, D. H., Kiss, E., Komp, C., Lelaure, V., Masuy, D., Palm, C., Peck, M. C., Pohl, T. M., Portetelle, D., Purnelle, B., Ramsperger, U., Surzycki, R., Thebault, P., Vandenbol, M., Vorholter, F. J., Weidner, S., Wells, D. H., Wong, K., Yeh, K. C., and Batut, J. 2001. The composite genome of the legume symbiont Sinorhizobium meliloti. Science 293:668-672.

Gordon, A. J., Minchin, F. R., James, C. L., and Komina, O. 1999. Sucrose synthase in legume nodules is essential for nitrogen fixation. Plant Physiol. 120:867-878.

Halket, J. M., Waterman, D., Przyborowska, A. M., Patel, R. K., Fraser, P. D., and Bramley, P. M. 2005. Chemical derivatization and mass spectral libraries in metabolic profiling by GC/MS and LC/MS/MS. J. Exp. Bot. 56:219-243.

Hirsch, A. M., Bang, M., and Ausubel, F. M. 1983. Ultrastructural analysis of ineffective alfalfa nodules formed by nif:Tn 5 mutants of Rhizobium meliloti. J. Bacteriol. 155:367-380.

Hohnjec, N., Becker, J. D., Pühler, A., Perlick, A. M., and Küster, H. 1999. Genomic organization and expression properties of the MtSucS1 gene, which encodes a nodule-enhanced sucrose synthase in the model legume Medicago truncatula. Mol. Gen. Genet. 261:514-522.

Hohnjec, N., Perlick, A. M., Pühler, A., and Küster, H. 2003. The Medicago truncatula sucrose synthase gene MtSucS1 is activated both in the infected region of root nodules and in the cortex of roots colonized by arbuscular mycorrhizal fungi. Mol. Plant-Microbe Interact. 16:903-915

Hohnjec, N., Vieweg, M. F., Pühler, A., Becker, A., and Küster, H. 2005. Overlaps in the transcriptional profiles of Medicago truncatula roots inoculated with two different Glomus fungi provide insights into the genetic program activated during arbuscular mycorrhiza. Plant Physiol. 137:1283-1301

Huhman, D. V., and Sumner, L. W. 2002. Metabolic profiling of saponins in Medicago sativa and Medicago truncatula using HPLC coupled to an electrospray ion-trap mass spectrometer. Phytochemistry 59:347360 .

Kahn, M. L., McDermott, T. R., and Udvardi, M. K. 1998. Carbon and nitrogen metabolism in Rhizobia. In: The Rhizobiaceae. H. P. Spaink, A. Kondorosi, and P. J. J. Hooykaas, eds. Kluwer Academic Publishers, Dordrecht, The Netherlands.

Kaminski, P. A., Batut, J., and Boistard, P. 1998. A survey of symbiotic nitrogen fixation by Rhizobia. Pages 431-460 in: The Rhizobiaceae. H. P. Spaink, A. Kondorosi, and P. J. J. Hooykaas, eds. Kluwer Academic Publishers, Dordrecht, The Netherlands.

Kanehisa, M., Goto, S., Hattori, M., Aoki-Kinoshita, K. F., Itoh, M., Kawashima, S., Katayama, T., Araki, M., Hirakawa, M. 2006. From genomics to chemical genomics: New developments in KEGG. Nucleic Acids Res. 34:D354-357.

Kopka, J., Schauer, N., Krueger, S., Birkemeyer, C., Usadel, B., Bergmuller, E., Dormann, P., Weckwerth, W., Gibon, Y., Stitt, M., Willmitzer, L., Fernie, A. R., Sand teinhauser, D. 2005. GMD@CSB.DB: The Golm Metabolome Database. Bioinformatics 21:1635-1638

Krol, E., and Becker, A. 2004. Global transcriptional analysis of the phosphate starvation response in Sinorhizobium meliloti strains 1021 and 2011. Mol. Genet. Genomics 272:1-17.

Lodwig, E., and Poole, P. 2003. Metabolism of Rhizobium bacteroids Crit. Rev. Plant Sci. 22:37-78.

Lodwig, E. M., Hosie, A. H., Bourdes, A., Findlay, K., Allaway, D., Karunakaran, R., Downie, J. A., and Poole, P. S. 2003. Amino-acid cycling drives nitrogen fixation in the legume-Rhizobium symbiosis. Nature 422:722-726.

Long, S. R. 1996. Rhizobium symbiosis: Nod factors in perspective. Plant Cell 8:1885-1898.

MacRae, J. C. 1971. Quantitative measurement of starch in very small amounts of leaf tissue. Planta 96:101-108

Masepohl, B., Witty, J. F., Riedel, K. U., Klipp, W., and Pühler, A. 1993. Rhizobium meliloti mutants defective in symbiotic nitrogen-fixation affect the oxygen gradient in alfalfa (Medicago sativa) root-nodules. J. Exp. Bot. 44:419-426.

Minchin, F. R. 1997. Regulation of oxygen diffusion in legume nodules. Soil Biol. Biochem. 29:881-888.

Mitra, R. M., and Long, S. R. 2004. Plant and bacterial symbiotic mutants define three transcriptionally distinct stages in the development of the Medicago truncatula/Sinorhizobium meliloti symbiosis. Plant Physiol. 134:595-604.

Müller, P., Hynes, M., Kapp, D., Niehaus, K., and Pühler, A. 1988. Two classes of Rhizobium meliloti infection mutants differ in exopolysaccharide production and in coinoculation properties with nodulation mutants. Mol. Gen. Genet. 211:17-26.

Niehaus, K., Kapp, D., and Pühler, A. 1993. Plant defence and delayed infection of alfalfa pseudonodules induced by an exopolysaccharide (EPS I)-deficient Rhizobium meliloti mutant. Planta 190:415-425.

Nielsen, T. H., Krapp, A., Röper-Schwarz, U., and Stitt, M. 1998. The sugar-mediated regulation of genes encoding the small subunit of Rubisco and the regulatory subunit of ADP glucose pyrophosphorylase is modified by phosphate and nitrogen. Plant Cell Environ. 21:443-454.

Parsons, R., and Sunley, R. J. 2001. Nitrogen nutrition and the role of rootshoot nitrogen signaling particularly in symbiotic systems. J. Exp. Bot. 52:435-443.

Patriarca, E. J., Tate, R., Ferraioli, S., and Iaccarino, M. 2004. Organogenesis of legume root nodules. Int. Rev. Cytol. 234:201-262.

Paul, M. J., and Driscoll, S. P. 1997. Sugar repression of photosynthesis: The role of carbohydrates in signaling nitrogen deficiency through source:sink imbalance. Plant Cell Environ. 20:110-116.

Pladys, D., and Vance, C. P. 1993. Proteolysis during development and senescence of effective and plant gene-controlled ineffective alfalfa nodules. Plant Physiol. 103:379-384.

Randhawa, G. S., and Hassani, R. 2002. Role of rhizobial biosynthetic pathways of amino acids, nucleotide bases and vitamins in symbiosis. Indian J. Exp. Biol. 40:755-764.

Roessner, U., Luedemann, A., Brust, D., Fiehn, O., Linke, T., Willmitzer, L., and Fernie, A. 2001. Metabolic profiling allows comprehensive phenotyping of genetically or environmentally modified plant systems. Plant Cell 13:11-29.

Rolfe, B. G., Gresshoff, P. M., and Shine, J. 1980. Rapid screening for symbiotic mutants of Rhizobium and white clover. Plant Sci. Lett. 19:277-284.

Rosendahl, L., Vance, C. P., and Pedersen, W. B. 1990. Products of dark $\mathrm{CO}_{2}$ fixation in pea root nodules support bacteroid metabolism. Plant Physiol. 93:12-19.

Ruvkun, G. B., Sundaresan, V., and Ausubel, F. M. 1982. Directed transposon Tn5 mutagenesis and complementation analysis of Rhizobium meliloti symbiotic nitrogen fixation genes. Cell 29:551-559.

Scheible, W. R., Gonzalez-Fontes, A., Lauerer, M., Muller-Rober, B., Caboche, M., and Stitt, M. 1997. Nitrate acts as a signal to induce organic acid metabolism and repress starch metabolism in tobacco. Plant Cell 9:783-798.

Scheible, W. R., Morcuende, R., Czechowski, T., Fritz, C., Osuna, D., Palacios-Rojas, N., Schindelasch, D., Thimm, O., Udvardi, M. K., and Stitt, M. 2004. Genome-wide reprogramming of primary and secondary metabolism, protein synthesis, cellular growth processes, and the regulatory infrastructure of Arabidopsis in response to nitrogen. Plant Physiol. 136:2483-2499.

Schultze, M., and Kondorosi, A. 1998. Regulation of symbiotic root nodule development. Annu. Rev. Genet. 32:33-57.

Schulze, J. 2004. How are nitrogen fixation rates regulated in legumes? J. Plant Nutr. Soil Sci. 167:125-137.

Soga, T., Ohashi, Y., Ueno, Y., Naraoka, H., Tomita, M., and Nishioka, T. 2003. Quantitative metabolome analysis using capillary electrophoresis mass spectrometry. J. Proteome Res. 2:488-494.

Starker, C. G., Parra-Colmenares, A. L., Smith, L., Mitra, R. M., and Long, S. R. 2006. Nitrogen fixation mutants of Medicago truncatula fail to support plant and bacterial symbiotic gene expression. Plant Physiol. 140:671-680.

Stitt, M., and Krapp, A. 1999. The interaction between elevated carbon dioxide and nitrogen nutrition: The physiological and molecular background. Plant Cell Environ. 22:583-621.

Stougaard, J. 2000. Regulators and regulation of legume root nodule development. Plant Physiol. 124:531-540.

Suganuma, N., Yamamoto, A., Itou, A., Hakoyama, T., Banba, M., Hata, S., Kawaguchi, M., and Kouchi, H. 2004. cDNA macroarray analysis of gene expression in ineffective nodules induced on the Lotus japonicus sen 1 mutant. Mol. Plant-Microbe Interact. 17:1223-1233.

Vance, C. P., and Gantt, J. S. 1992. Control of nitrogen and carbon me- 
tabolism in root nodules. Physiol. Plant 85:266-274.

Vance, C. P., Gregerson, R. G., Robinson, D. L., Miller, S. S., and Gantt, J. S. 1994. Primary assimilation of nitrogen in alfalfa nodules: Molecular features of enzymes involved. Plant Sci. 101:51-64.

Vance, C. P., and Heichel, G. H. 1991. Carbon in N2 fixation: Limitation or exquisite adaptation. Annu. Rev. Plant Physiol. Plant Mol. Biol. 42:373-392.

Vincent, J. M. 1980. Factors controlling the legume-Rhizobium symbiosis. Pages 103-127 in: Nitrogen Fixation Volume II: Symbiotic Associations and Cyanobacteria. W. E. Newton and W. H. Orme-Johnson, eds. University Park Press, Baltimore, U.S.A

\section{AUTHOR-RECOMMENDED INTERNET RESOURCES}

ArrayExpress webpage: www.ebi.ac.uk/arrayexpress

The Institute for Genomic Research (TIGR) Medicago Gene Index:

www.tigr.org/tigr-scripts/tgi/T_index.cgi?species=medicago 